$\underline{\text { Pablo Cobo Gálvez }}{ }^{1}$

\title{
El desarrollo e implantación del Sistema para la Autonomía y Atención a la Dependencia y de sus prestaciones desde la Administración General del Estado: normas y criterios comunes
}

SUMARIO: I. EL SISTEMA PARA LA AUTONOMÍA Y ATENCIÓN A LA DEPENDENCIA: CARACTERÍSTICAS ESENCIALES. I.1. UNA NUEVA MODALIDAD DE PROTECCIÓN SOCIAL EN EL MARCO DE LOS SERVICIOS SOCIALES. I.2. UN DERECHO SUBJETIVO DE CIUDADANÍA. I.3. UN MODELO BASADO EN LA COOPERACIÓN TERRITORIAL. I.4. UN MODELO DE GESTIÓN DESCENTRALIZADA. I.5. UN MODELO BASADO EN LA PARTICIPACIÓN. II. EL DESARROLLO DE LA VALORACIÓN DE LA DEPENDENCIA COMO GARANTÍA DE IGUALDAD EN EL ACCESO A LAS PRESTACIONES DEL SISTEMA. III. EL DESARROLLO DEL RÉGIMEN DE PRESTACIONES. IV. EL DESARROLLO DE LA FINANCIACIÓN DEL SISTEMA. IV.1. NIVEL MÍNimo de protección. IV.2. Nivel aCordado. IV.3. Determinación de la CapaCiDAD ECONÓMICA Y PARTICIPACIÓN DE LOS BENEFICIARIOS EN EL COSTE DE LOS SERVICIOS y PRESTACIONEs. a) La determinación de la capacidad económica. b). Criterios de participación económica del beneficiario en las prestaciones del SAAD. V. BIBLIOGRAFÍA.

\footnotetext{
${ }^{1}$ Subdirector General de Planificación, Ordenación y Evaluación del IMSERSO.
} 
Mediante la aprobación de la Ley 39/2006, de 14 de diciembre, de Promoción de la Autonomía Personal y Atención a las personas en situación de dependencia, que entró en vigor el 1 de enero de 2007, se viene a instaurar, en nuestra legislación, un nuevo sistema de atención a las personas en situación de dependencia y de promoción de su autonomía personal que constituye uno de los principales retos de la política social, atender las necesidades de aquellas personas que, por encontrarse en situación de especial vulnerabilidad, requieren ayuda para desarrollar las actividades esenciales de la vida diaria y alcanzar una mayor autonomía personal.

Siguiendo los mandatos contenidos en los artículos 49 y 59 del texto constitucional, referentes a la atención a personas con discapacidad y a personas mayores, la Ley regula las condiciones básicas de promoción de la autonomía personal y de atención a las personas en situación de dependencia a través de la creación e implantación de un Sistema para la Autonomía y Atención a la Dependencia (SAAD), configurando un derecho basado en los principios de universalidad, y acceso a las prestaciones en condiciones de igualdad, con la colaboración y participación de todas las Administraciones Públicas y la garantía por la Administración General del Estado de un contenido mínimo común de derechos para todos los ciudadanos en cualquier parte del territorio español.

En consecuencia, el Sistema para la Autonomía y Atención a la Dependencia se configura como una acción coordinada y cooperativa de la Administración General del Estado y las Comunidades Autónomas con la participación de las Entidades Locales, para desarrollar los mecanismos e instrumentos necesarios para hacer frente a las necesidades derivadas de las situaciones de dependencia.

Es mi intención analizar en este capítulo la configuración y el desarrollo del SAAD desde la aprobación de la Ley, tomando como referencia para el análisis lo establecido en el articulado de la Ley con los acuerdos adoptados por el Consejo Territorial y las disposiciones reglamentarias aprobadas por el Gobierno.

\section{EL SISTEMA PARA LA AUTONOMÍA Y ATENCIÓN A LA DEPENDENCIA: CARACTERÍSTICAS ESENCIALES}

La Ley 39 /2006 dedica el Capítulo I a regular el Sistema para la Autonomía Personal y Atención a la Dependencia. Aunque no existe una definición de en qué consiste formalmente el Sistema, a lo largo del articulado se va configurando a través de la determinación de su finalidad, el establecimiento de los niveles de protección, la concreción de las prestaciones de dependencia que se garantizan, la participación de las distintas Administra- 
ciones Públicas en su gestión y financiación y el ámbito subjetivo de protección, definiendo los grados y niveles de dependencia y su valoración.

El diccionario de la Real Academia define Sistema como "conjunto de reglas o principios sobre una materia racionalmente enlazados entre sí" o "conjunto de cosas que relacionadas entre sí ordenadamente contribuyen a determinado objeto".

Se ha debatido, a nivel político administrativo en las reuniones de Directores Generales de las Comunidades Autónomas con el IMSERSO, si el SAAD tal y como se regula en la ley es un verdadero sistema o si por el contrario, como quiera que la dependencia forma parte de los servicios sociales, este término debería reservarse para definir a éstos. De cualquier forma, se puede decir que se dan los requisitos necesarios para que al conjunto de elementos (fines, niveles y modalidades de protección, gestión y financiación), que operan con interdependencia y se interrelacionan para lograr el objetivo común de promoción de la autonomía y atención a la dependencia, se le denomine Sistema, sin perjuicio de que pueda integrarse en un sistema más amplio de servicios sociales o de bienestar social si incorporamos la Sanidad y la Seguridad Social.

No existe, sin embargo, un ente con personalidad jurídica propia que represente al Sistema en su integridad, aunque si se ha creado un Consejo Territorial como órgano de coordinación. La dirección y representación le corresponde a los órganos que las Comunidades Autónomas determinen en su respectivo territorio y al Ministerio, a través del IMSERSO, en su ámbito competencial.

El SAAD nace con las siguientes finalidades ${ }^{2}$ :

- Garantizar las condiciones básicas y el contenido común en todo el territorio del Estado.

- Servir de cauce para la colaboración y participación de las distintas Administraciones Públicas.

- Optimizar los recursos públicos y privados disponibles, para lo cual establece una red de centros y servicios del Sistema.

Podemos decir que el legislador al determinar estos fines está pensando, por una parte, en aquellos aspectos comunes de la protección que deben

2 Art. 6: "1. El Sistema para la Autonomía y Atención a la Dependencia garantiza las condiciones básicas y el contenido común a que se refiere la presente Ley; sirve de cauce para la colaboración y participación de las Administraciones Públicas, en el ejercicio de sus respectivas competencias, en materia de promoción de la autonomía personal y la atención y protección a las personas en situación de dependencia; optimiza los recursos públicos y privados disponibles, y contribuye a la mejora de las condiciones de vida de los ciudadanos". 
darse en todo el territorio del Estado (que analizaremos con detalle más adelante) y, por otra, en el Consejo territorial como órgano de cooperación del SAAD.

En este mismo artículo, en el que se define la finalidad del Sistema, se dice que "el Sistema se configura como una red de utilización pública que integra, de forma coordinada, centros y servicios, públicos y privados". Así definida, esta configuración resulta insuficiente, considero que el SAAD es más que los centros y servicios que se ponen a disposición de los ciudadanos, es también la protección que se ofrece, las intensidades de los servicios y la cuantía de las prestaciones económicas, además del procedimiento de financiación.

\section{I.1. El Sistema para la Autonomía Personal y Atención a la Dependencia (SAAD) una nueva modalidad de protección SOCIAL EN EL MARCO DE LOS SERVICIOS SOCIALES}

El SAAD amplía y complementa la acción protectora del Estado y del Sistema de la Seguridad Social, potenciando el avance del modelo de Estado social que consagra la Constitución Española y promoviendo el compromiso de todos los poderes públicos para dotar de los recursos necesarios para hacer efectivo un sistema de servicios sociales de calidad, garantista y plenamente universal. En la exposición de motivos de la Ley se dice:

"La necesidad de garantizar a los ciudadanos, y a las propias Comunidades Autónomas, un marco estable de recursos y servicios para la atención a la dependencia y su progresiva importancia lleva ahora al Estado a intervenir en este ámbito con la regulación contenida en esta Ley, que la configura como una nueva modalidad de protección social que amplía y complementa la acción protectora del Estado y del Sistema de la Seguridad Social.

Se trata ahora de configurar un nuevo desarrollo de los servicios sociales del país que amplíe y complemente la acción protectora de este sistema, potenciando el avance del modelo de Estado social que consagra la Constitución Española, potenciando el compromiso de todos los poderes públicos en promover y dotar los recursos necesarios para hacer efectivo un sistema de servicios sociales de calidad, garantistas y plenamente universales. En este sentido, el Sistema de Atención de la Dependencia es uno de los instrumentos fundamentales para mejorar la situación de los servicios sociales en nuestro país, respondiendo a la necesidad de la atención a las situaciones de dependencia y a la promoción de la autonomía personal, la calidad de vida y la igualdad de oportunidades." ${ }^{3}$

${ }^{3}$ Ley 39/2007, de 14 de diciembre, de Promoción de la Autonomía Personal y Atención a las personas en situación de dependencia. Exposición de motivos 1 . 
Tres aspectos merecen la pena destacarse; el primero, estamos ante un nuevo desarrollo constitucional del Estado social de derecho que promueve nuestra constitución, en cumplimiento del mandato a los poderes públicos de los artículos 49 y 50 de la Carta máxima, por el que se garantiza la protección de aquellas personas con discapacidad y mayores en situación de dependencia; el segundo, la protección se hace efectiva mediante la creación de un nuevo Sistema que viene a ampliar los sistemas de protección ya existentes, el sanitario, el de servicios sociales y el de seguridad social; el tercero hace referencia al marco en el que ha de desarrollarse este nuevo sistema, que no es otro que el de los servicios sociales que actualmente se presta por las Comunidades Autónomas.

Los derechos garantizados por las leyes pretenden asegurar un nivel mínimo de servicios que faciliten a los ciudadanos su desarrollo personal a través de las prestaciones de servicios de las Administraciones Públicas. En este sentido, la Constitución Española, a lo largo de su articulado, establece mandatos a los poderes públicos que garanticen la protección pública de los ciudadanos y, en particular, de las personas mayores o con discapacidad. Siguiendo el análisis de estos mandatos de lo general a lo particular, queda justificada la acción reguladora en esta materia. El artículo 9.2 establece que "corresponde a los poderes públicos promover las condiciones para que la libertad y la igualdad del individuo y de los grupos en que se integran sean reales y efectivas; remover los obstáculos que impidan o dificulten su plenitud y facilitar la participación de todos los ciudadanos en la vida política, económica, cultural y social". Asimismo, el artículo 41 alude a que "los poderes públicos mantendrán un régimen público de Seguridad Social para todos los ciudadanos, que garantice la asistencia y prestaciones sociales suficientes ante situaciones de necesidad...”. El artículo 49 obliga a los poderes públicos a realizar una política de integración social de los ciudadanos con discapacidad "para el disfrute de los derechos que éste título otorga a todos los ciudadanos". Y el artículo 50, en fin, insta a los poderes públicos a garantizar "mediante pensiones adecuadas y periódicamente actualizadas, la suficiencia económica a los ciudadanos durante la tercera edad. Asimismo, y con independencia de las obligaciones familiares, promoverán su bienestar mediante un sistema de servicios sociales que atenderán sus problemas específicos de salud, vivienda, cultura y ocio".

El segundo aspecto, al que me refería anteriormente, es la creación de un nuevo Sistema que amplía y complementa los servicios y prestaciones ya existentes en el ámbito del Estado y de la Seguridad Social.

No es cuestión, en este momento (algunas reflexiones se hacen en el primer capítulo de este monográfico), de analizar las razones a favor y en contra de que el nuevo sistema de protección se situara en el marco de la Seguridad Social, pero sí cabe afirmar que ello ha condicionado el conteni- 
do de la ley, su tramitación parlamentaria y su desarrollo y aplicación para bien y para mal.

El tercer aspecto se refiere a la relación del SAAD con el sistema de servicios sociales. Este tema ha constituído uno de los asuntos más polémicos durante el período entre la aprobación del anteproyecto y el proyecto por el Consejo de Ministros. La mayor parte de los expertos ${ }^{4}$, así como de las Instituciones que se manifestaron sobre el tema se inclinaban porque el Sistema de la Dependencia formara parte de la Seguridad Social. Este asunto fue resuelto en el texto que se envía al Congreso y mejorado durante la tramitación parlamentaria.

En las reuniones de las Comunidades Autónomas con el IMSERSO, a nivel de Directores Generales, se adopta el acuerdo de vincular la protección de la dependencia a los servicios sociales. Tienen especial relevancia las observaciones respecto del diseño del modelo de gestión, que se formulan en este ámbito, acordando que "la puerta de entrada al Sistema" se realice a través de los servicios sociales municipales.

También los centros de servicios sociales y las organizaciones profesionales de los mismos contribuyeron a mejorar el texto del proyecto en el trámite parlamentario.

Además de la referencia expresa de la exposición de motivos, citada anteriormente, el artículo 16, apartado 1 establece que "las prestaciones y servicios establecidos en esta Ley se integran en la Red de Servicios Sociales de las respectivas Comunidades Autónomas en el ámbito de las competencias que las mismas tienen asumidas". Especial relevancia tiene la redacción del artículo 29 sobre el programa individual de atención "En el marco del procedimiento de reconocimiento de la situación de dependencia y las prestaciones correspondientes, los servicios sociales correspondientes del sistema público establecerán, un Programa Individual de Atención en el que se determinarán las modalidades de intervención más adecuados a sus necesidades...”.

\section{I.2. LA PROMOCIÓN DE LA AUTONOMÍA Y LA ATENCIÓN A LA DEPENDENCIA UN DERECHO SUBJETIVO DE CIUDADANÍA}

La Ley de Promoción de la Autonomía Personal y Atención a las personas en situación de dependencia establece en su frontispicio que "la presente Ley tiene por objeto regular las condiciones básicas que garanticen la

\footnotetext{
${ }^{4}$ Rodríguez Cabrero, Gregorio: La protección social de la dependencia en España, Fundación Alternativas, n. ${ }^{\circ}$ 44//2004.

Rodríguez Rodríguez, Pilar: El Sistema de Servicios Sociales español y las necesidades derivadas de la atención a la dependencia, Fundación Alternativas, n. ${ }^{\circ}$ 87/2006.
} 
igualdad en el ejercicio del derecho subjetivo de ciudadanía a la promoción de la autonomía personal y atención a las personas en situación de dependencia, en los términos establecidos en las leyes." 5 No suele ser habitual que las leyes en las que se reconocen derechos califiquen su naturaleza. No lo hacen ni la Ley General de Seguridad Social, ni la Ley General de Sanidad, ni las sucesivas leyes de educación. Es a la doctrina a quien le corresponde, en función de su regulación, opinar sobre ello.

Considero que la ley define con precisión el derecho y su alcance cuando afirma "Las personas en situación de dependencia tendrán derecho, con independencia del lugar del territorio del Estado español donde residan, a acceder, en condiciones de igualdad, a las prestaciones y servicios previstos en esta Ley, en los términos establecidos en la misma" "

¿Por qué si esto es así, en esta Ley en particular se califican como de derecho subjetivo y de ciudadanía los servicios y prestaciones que establece?

En la negociación con los agentes sociales este aspecto constituye uno de los elementos fundamentales. Piden expresamente que figure en el acuerdo a suscribir, porque nadie discute en este país que las prestaciones de seguridad social a la jubilación, invalidez, viudedad, o cualquiera otra de las establecidas, son un derecho subjetivo de los ciudadanos que reúnan los requisitos establecidos en la ley; ahora bien, si la protección de la dependencia se residencia fuera del marco de la seguridad social se consideró que era necesario remarcar el carácter de derecho y la capacidad del ciudadano de reclamarlo.

El proyecto de ley aprobado por el Gobierno no dice expresamente que sea un derecho subjetivo, es en el trámite parlamentario en el Congreso, en el que se acepta una enmienda del Grupo Socialista y de los Grupos de Ezquerra Republicana e Izquierda Unida en la que se propone y acepta la siguiente redacción: "La presente Ley tiene por objeto regular las condiciones básicas que garanticen la igualdad en el ejercicio del derecho subjetivo de ciudadanía a la promoción de la autonomía personal y atención a las personas en situación de dependencia, en los términos establecidos en las leyes". Con esta enmienda se recoge la posición de un sector importante de la sociedad, sindicatos, asociaciones de personas mayores, de discapacitados y de profesionales, que piden mayor precisión y concreción tanto sobre la naturaleza del derecho como sobre las condiciones de igualdad para su ejercicio.

El derecho subjetivo consiste en la facultad o poder de hacer valer los derechos propios, limitar los ajenos, poseer o exigir algo conforme a la norma jurídica. Conlleva dos elementos sustanciales: El interno de "poder" o "señorío", la posibilidad de hacer o querer conforme al imperativo jurídico

\footnotetext{
5 Ley 39/2006. Art. 1.

${ }^{6}$ Ley 39/2006. Art. 4. 1.
} 
y dentro de sus límites. Por ejemplo, la capacidad del dueño de una finca para explotarla, arrendarla, venderla, según la ley; y el formal o externo de "pretensión", que consiste en la posibilidad de exigir de otra persona su concesión y el respeto de su poder o señorío y, consecuentemente, en la posibilidad de reaccionar contra toda perturbación que se le ocasione en el ejercicio de aquél, también dentro del limite del ordenamiento jurídico.

El derecho subjetivo presupone de normas objetivas donde se encuentren establecidos los supuestos de hecho o hipótesis legales, que sustenten la acción que el sujeto pretenda ejercer. En este supuesto las normas que dan cobertura al derecho son la ley de Promoción de la Autonomía Personal y Atención a las personas en situación de dependencia y aquellas que por razón de la materia le sean de aplicación.

La legitimidad para ejercer el derecho subjetivo se refiere al conjunto de condiciones que la norma objetiva exige a los sujetos que pretendan accionarlo. Es la propia disposición legal, en su contexto con las otras normas del ordenamiento jurídico, la que condiciona los requisitos que debe reunir la persona para que por sí misma pueda tener la legitimidad que la ley exige para ejercer validamente su derecho.

Los derechos subjetivos garantizan también la posibilidad de ejercitar una serie de pretensiones por parte de los titulares del mismo, que tienen por finalidad la intervención de otros sujetos en su proceso de realización. Esta intervención puede consistir en el cumplimiento de las obligaciones (positivas o negativas) que forman parte de la estructura del derecho o en la adopción de medidas jurídicas de protección.

Este es un derecho que por razón del carácter del sujeto frente al que se tiene interés o poder jurídicamente protegido, tiene la condición de los derechos subjetivos públicos, que son los que atribuyen facultades que corresponden a los sujetos en sus relaciones con el Estado, frente a los derechos subjetivos privados, que son aquéllos cuyo contenido de facultades o posibilidades de acción tiene como correlato inmediato el comportamiento de sujetos particulares.

A los efectos de esta ley el derecho subjetivo ha de entenderse como la facultad o poder que tiene la persona, que reúna los requisitos exigidos, para solicitar el reconocimiento de la condición de dependencia y disfrutar de las prestaciones que le correspondan y exigir de los demás que no lo perturben o interfieran.

Una manifestación del ejercicio de derecho subjetivo es la de posibilitar su defensa recurriendo ante los órganos de la Administración o judiciales en el supuesto de considerar que su derecho no ha sido adecuadamente satisfecho. La ley entre los derechos de las personas en situación de dependencia señala precisamente el de "iniciar las acciones administrativas y jurisdiccio- 
nales en defensa del derecho que reconoce la presente Ley en el apartado 1 de este artículo. En el caso de los menores o personas incapacitadas judicialmente, estarán legitimadas para actuar en su nombre quienes ejerzan la patria potestad o quienes ostenten la representación legal" 7

El derecho de ciudadanía que predica la norma respecto de la promoción de la autonomía y atención a la dependencia no queda explicitado en su alcance. Este término, que empieza a ser normal en la terminología política, es relativamente nuevo en el ámbito legislativo nacional, aunque es bastante común en las disposiciones europeas. El concepto de derecho de ciudadanía varía respecto de a que ciudadano nos referimos; si al nacional estatal que tendría plenos derechos, al comunitario con iguales derechos en algunas materias y reducidos en otras, o al extracomunitario que tiene limitados sus derechos sobre los ciudadanos nacionales a aquellos que expresamente le son reconocidos por la ley de extranjería.

Cabe hacer una primera interpretación de cuando la ley se refiere a este derecho como un derecho de ciudadanía, lo hace porque entiende que son titulares del mismo todos los ciudadanos por el hecho de serlo, sin ningún otro requisito específico distinto que pudiera excluirlo. No tendrían por tanto la consideración de derechos de ciudadanía las pensiones de jubilación contributivas, en tanto en cuanto para ser beneficiario de ellas se precisa como requisito, además de tener la edad de 65 años, haber cotizado a la Seguridad Social durante un número determinado de años.

Hablar de derecho de ciudadanía es hacerlo de derecho universal para todos. La ley así lo proclama entre sus principios: "La universalidad en el acceso de todas las personas en situación de dependencia, en condiciones de igualdad efectiva y no discriminación, en los términos establecidos en esta Ley" 8 .

La declaración que hace la ley de derecho subjetivo y de ciudadanía lo hace precisando "en los términos establecidos en las leyes". Por lo tanto, han de cumplirse los requisitos y condiciones establecidos en ella para ser titulares del derecho: Ser español y cumplir los siguientes requisitos?

a) Encontrarse en situación de dependencia en alguno de los grados establecidos. (Para los menores de 3 años se establecen especificaciones en sistema de valoración y en el régimen prestacional).

La Ley en el trámite parlamentario suprimió el requisito de exclusión de los menores de 3 años, que se regulaban en una disposición adicional, e in-

\footnotetext{
7 Ley 39/2006. Art. 4. 2.

${ }^{8}$ Ley 39/2006. Art. 3 b).

9 Ley 39/2006. Art. 5.
} 
corporó el inciso con la referencia a la protección especial a los menores de 3 años de la disposición adicional tercera. Esta modificación no amplía la protección de estos niños, que se seguirán rigiendo por el régimen prestacional especial de la disposición citada, pero evita en el texto articulado la apariencia de desprotección a que daba lugar la redacción del Proyecto de Ley.

b) Residir en territorio español y haberlo hecho durante cinco años, de los cuales dos deberán ser inmediatamente anteriores a la fecha de presentación de la solicitud. Para los menores de cinco años el período de residencia se exigirá a quien ejerza su guarda y custodia.

Una de las primeras cuestiones que se plantean es el alcance del derecho respecto de los ciudadanos europeos residentes en España, a la vista de lo regulado en esta ley y a las disposiciones y jurisprudencia de la Unión Europea (UE).

La ley 39/2006, establece: "Las personas que, reuniendo los requisitos anteriores (estar en situación de dependencia y residencia en España), carezcan de la nacionalidad española se regirán por lo establecido en la Ley Orgánica 4/2000, de 11 de enero, sobre derechos y libertades de los extranjeros en España y su integración social, en los tratados internacionales y en los convenios que se establezcan con el país de origen" ${ }^{10}$. De conformidad con este apartado a los ciudadanos europeos residentes en España habrá de aplicárseles lo dispuesto en los tratados internacionales de la UE, así como las normas que lo desarrollan y la interpretación que sobre las mismas realiza la jurisprudencia del Tribunal de Justicia de las Comunidades Europeas (TJCE). Sin embargo, se plantea la duda sobre qué normativa, en concreto de la UE, le es de aplicación respecto de las prestaciones de dependencia, si le es o no de aplicación el Reglamento 1408/71. Sobre este asunto ya ha habido reflexiones de los expertos ${ }^{11}$. A la vista de las sentencias del TJCE (0-160/96 "Molineaar", 0-215/99 "Jauch" y 286/039 "Hosse"), se plantean dudas sobre si las prestaciones de dependencia, tal y como se configuran en la ley, pueden quedar excluidas del ámbito de aplicación del citado Reglamento, teniendo en cuenta que su inclusión o no, según el criterio del Tri-

${ }^{10}$ Ley 39/2006. Art. 5. 2.

${ }^{11}$ García de Cortázar, Carlos: "Libre circulación de pacientes en la Unión Europea. La atención a la dependencia y la tarjeta sanitaria europea”, Revista del Ministerio de Trabajo y Asuntos Sociales, núm. 47, 2004.

Panizo Robles, José Antonio: "La cobertura social de la dependencia”, Revista de Trabajo y Seguridad Social, núm. 286. 
bunal, se fundamenta en los elementos constitutivos de cada prestación, en su finalidad y en los requisitos exigidos para su concesión, independientemente de que la prestación se encuentre o no definida como prestación de seguridad social por la legislación nacional del país. La primera de las sentencias se refiere a la aplicación del sistema alemán y las otras dos al austriaco; ambos sistemas se enmarcan claramente en el modelo de seguridad social con cotizaciones específicas para este fin. No obstante, la naturaleza no contributiva de las prestaciones no es considerada por el TJCE como causa de no inclusión en el Reglamento. Asimismo, el TJCE ha estimado que la inclusión de una prestación en el Anexo II de Reglamento 1407/71 no es suficiente para que no le sea de aplicación el mismo.

Los efectos resultantes de la consideración de estas prestaciones como de seguridad social daría lugar a la aplicación del principio de igualdad de trato, lo que supone la equiparación de los ciudadanos de la UE a los nacionales y, en consecuencia, a la exportabilidad de las prestaciones económicas cuando el beneficiario traslade su residencia a otro Estado. Las prestaciones de servicio o en especie, en terminología europea, tendrían la consideración de prestaciones complementarias de enfermedad y, por lo tanto, reembolsables por el país de origen.

Se plantea una segunda cuestión relacionada con el alcance de este derecho, por una parte en relación con los españoles no residentes en España y, por otra, respecto de los emigrantes españoles retornados que no cumplen el requisito de residencia establecido de cinco años y dos inmediatamente anteriores a la fecha de presentación de la solicitud. La Ley establece que "el Gobierno podrá establecer medidas de protección a favor de los españoles no residentes en España". Y que asimismo "establecerá, previo acuerdo del Consejo Territorial del Sistema para la Autonomía y Atención a la Dependencia, las condiciones de acceso al Sistema de Atención a la Dependencia de los emigrantes españoles retornados" 12 .

Respecto del primer supuesto, el Gobierno todavía no ha establecido medidas concretas de protección, aunque el Estatuto de la ciudadanía española en el exterior contempla dos medidas concretas ${ }^{13}$ : "Los poderes públicos prestarán especial apoyo, en particular económico, a aquellos centros y asociaciones de españoles en el exterior y retornados en el Estado español que cuenten con infraestructuras adecuadas para la atención de personas mayores o en situación de dependencia. Se incentivarán las redes que generen un mejor aprovechamiento de los recursos públicos".

${ }^{12}$ Ley 39/2006. Art. 53 y 4.

${ }^{13}$ Ley 40/2006, de 14 de diciembre, del Estatuto de la ciudadanía española en el exterior. Art. 20.3. 
"Los poderes públicos, en el marco de la regulación de la atención a la dependencia, desarrollarán medidas específicas, especialmente de carácter asistencial, sanitario y farmacéutico, encaminadas a la consecución del bienestar integral de la ciudadanía española en el exterior en situación de necesidad, en aras de alcanzar la gradual asimilación a las prestaciones vigentes del Sistema para la Autonomía y Atención a la Dependencia, conforme a lo que disponga la legislación vigente".

Para el segundo de los supuestos el Gobierno ha regulado, previo acuerdo del Consejo Territorial, la protección de los emigrantes españoles retornados con igual contenido y extensión que las prestaciones y ayudas económicas reguladas en la misma, de conformidad con las siguientes $\operatorname{pautas}^{14}$ :

- El coste de los servicios y prestaciones económicas será asumido por la Administración General del Estado y la correspondiente Comunidad Autónoma, en la forma establecida en el artículo 32 de la Ley 39/2006, de 14 de diciembre.

- El beneficiario participará según su capacidad económica en la financiación de las prestaciones, que será también tenida en cuenta para determinar la cuantía de las prestaciones económicas.

- Las prestaciones se reconocerán siempre a instancia de los emigrantes españoles retornados y se extinguirán, en todo caso, cuando el beneficiario, por cumplir el período exigido de residencia en territorio español, pueda acceder a las prestaciones del Sistema para la Autonomía y Atención a la Dependencia.

\section{I.3. UN MODELO BASADO EN LA COOPERACIÓN TERRITORIAL}

La Ley no solo proclama la cooperación interadministrativa entre sus principios $^{15}$, sino que incluso regula los órganos y los instrumentos de colaboración que han de hacerlo posible. Se crea un Consejo Territorial, como órgano esencial para el desarrollo y aplicación del Sistema, constituido por representantes de la Administración General del Estado y de las Comunidades Autónomas.

${ }^{14}$ Real Decreto 727/2007, de 8 de junio, sobre criterios para determinar las intensidades de protección de los servicios y la cuantía de las prestaciones económicas de la Ley 39/2006, de 14 de diciembre, de Promoción de la Autonomía Personal y Atención a las personas en situación de dependencia, Disposición adicional.

15 Ley 39/2007, de 14 de diciembre, de Promoción de la Autonomía Personal y Atención a las personas en situación de dependencia. Art. 3. ñ). 
El Consejo Territorial tiene la misión de configurar un Sistema para la Autonomía y Atención a la dependencia homogéneo en todo el territorio del Estado, al mismo tiempo que respetuoso con las peculiaridades que cada Comunidad Autónoma desee establecer en el ejercicio de sus respectivas competencias.

Al Consejo le corresponde desarrollar las funciones que constituyen los elementos esenciales del Sistema ${ }^{16}$ :

- Acordar el marco de cooperación para el desarrollo y financiación de la Ley.

- Establecer los criterios para determinar la intensidad de protección de los servicios.

- Acordar las condiciones y cuantía de las prestaciones económicas.

- Adoptar los criterios de participación del beneficiario en el coste de los servicios.

- Acordar el baremo común para determinar el acceso a los servicios y prestaciones, así como los criterios básicos del procedimiento de valoración y de las características de los órganos de valoración.

El resto de las funciones del Consejo Territorial contribuyen a destacar la importancia de este órgano y a configurarlo como "cauce de cooperación, comunicación e información entre las Administraciones Públicas".

La aplicación del SAAD deberá hacerse teniendo en cuenta el reparto de funciones entre las diferentes administraciones. La ley destaca la participación de la Administración General del Estado, de las Comunidades Autónomas y de las Entidades Locales y desarrolla los procedimientos de cooperación entre la Administración General del Estado y las Comunidades Autónomas, mediante convenios entre ambas administraciones en los que se acordarán los objetivos, medios y recursos para la aplicación de los servicios y prestaciones del SAAD, incrementando el nivel mínimo de protección fijado por el Estado ${ }^{17}$.

Este régimen de cooperación es la gran novedad de esta ley. No hubiera sido posible la creación de este sistema de protección de la dependencia, que reconozca un derecho para todos los ciudadanos del Estado, sin recurrir a procedimientos de colaboración entre las distintas administraciones.

Para ello, la Ley prevé un ámbito de cooperación extraordinariamente formalizado, en el que, de forma absolutamente novedosa, el desarrollo regla-

16 Ley 39/2007, Art. 8.

17 Ley 39/2007, de 14 de diciembre, de Promoción de la Autonomía Personal y Atención a las personas en situación de dependencia. Art. 10. Cooperación entre la Administración General del Estado y las Comunidades Autónomas. 
mentario que la Ley atribuye al Estado se condiciona al previo acuerdo de Estado y Comunidades Autónomas en el Consejo territorial. Esta atribución de competencias, tan relevantes, al Consejo Territorial plantea la cuestión de qué hubiera ocurrido si el Consejo no hubiera sido capaz de llegar a acuerdos sobre los aspectos fundamentales de desarrollo antes señalados. La contestación no puede ser otra que la Ley no hubiera podido desarrollarse. De ahí la importancia que, en su momento, tuvo la aprobación del reglamento del Consejo, especialmente en lo que se refiere al régimen de adopción de acuerdos. Ello dio lugar a un recurso contencioso de las Comunidades Autónomas de Madrid y Murcia, en el que se cuestionaba el régimen previsto de adopción de acuerdos por mayorías, pidiendo la unanimidad. La sentencia de la Sala afortunadamente ha desestimado el recurso, pues en caso contrario una sola Comunidad Autónoma hubiera podido paralizar el desarrollo de la Ley

La importancia y papel que debe jugar este órgano se advierte ya en su composición, puesto que en su seno tienen cabida representantes de todas las Administraciones Públicas, con lo que se persigue que las decisiones emanadas del Consejo cuenten con el mayor respaldo posible y sean fruto de un consenso por parte de los sujetos que, en última instancia, serán los responsables de llevar a la práctica lo dispuesto en la Ley 39/2006.

Hasta la fecha el citado Consejo ha adoptado varios acuerdos imprescindibles para avanzar en la implantación del SAAD y que con posterioridad han devenido en la correspondiente normativa reguladora:

- Marco de cooperación interadministrativa y criterios de reparto de créditos de la Administración General del Estado para la financiación del nivel acordado.

- Acuerdo sobre los criterios para determinar las intensidades de protección de los servicios, la compatibilidad e incompatibilidad entre los mismos y la protección de los beneficiarios desplazados, así como de los emigrantes españoles retornados.

- Acuerdo sobre condiciones de acceso y cuantía de las prestaciones económicas.

Acuerdo sobre valoración de la autonomía personal y dependencia.

\section{I.4. UN MODELO DE GESTIÓN DESCENTRALIZADA}

A las Comunidades Autónomas les corresponde, como administración competente en servicios sociales, todas las funciones relacionadas con la aplicación del Sistema ${ }^{18}$ :

18 Ley 39/2007, Art. 11.1. 
- La planificación, ordenación y dirección de los servicios de promoción de la autonomía personal y de atención a las personas en situación de dependencia.

- La gestión de la valoración y atención de la dependencia, de las prestaciones de dependencia y de los recursos en centros y servicios necesarios, facilitando la debida acreditación que garantice el cumplimiento de los requisitos y los estándares de calidad.

- La coordinación sociosanitaria.

- La creación y actualización del Registro de Centros y Servicios

- La garantía del cumplimiento de los requisitos y los estándares de calidad.

- La inspección de los servicios y prestaciones

- La evaluación del funcionamiento del Sistema en su territorio respectivo.

Sin perjuicio de las funciones anteriores, las Entidades Locales tienen atribuidas competencias específicas en esta materia que se enmarcan en la descentralización de los servicios en aquella administración más próxima al ciudadano. La ley establece que "Las Entidades Locales participarán en la gestión de los servicios de atención a las personas en situación de dependencia, de acuerdo con la normativa de sus respectivas Comunidades Autónomas y dentro de las competencias que la legislación vigente les atribuye" ${ }^{19}$.

La Ley reguladora de las Bases del Régimen Local ${ }^{20}$ establece que, para la gestión de sus intereses, el Municipio puede promover toda clase de actividades y prestar cuantos servicios públicos contribuyan a satisfacer las necesidades y aspiraciones de la comunidad vecinal, así como que ejercerá, entre otras, competencias en prestación de los servicios sociales y de promoción y reinserción social, en los términos que la legislación del Estado y de las Comunidades Autónomas establezcan.

Las Entidades Locales desarrollan actualmente importantes funciones en la atención a las personas en situación de dependencia, especialmente en servicios de ayuda a domicilio. Por otra parte, la propia Ley de Promoción de la Autonomía Personal y Atención a las personas en situación de dependencia les confía específicamente, a través de los servicios sociales correspondientes del Sistema Público, la competencia de elaboración del programa individual de atención ${ }^{21}$. Sin perjuicio de las competencias anteriormente señaladas, le co-

19 Ley 39/2007, Art. 12.1.

${ }^{20}$ Ley 7/1985, de 2 de abril, Reguladora de las Bases del Régimen Local (BOE n. ${ }^{\circ} 80$, de 3 de abril de 1985) Art. 25.

${ }^{21}$ Ley 39/2007, Art. 29. 
rresponde a las Comunidades Autónomas determinar el alcance de descentralización en sus respectivos territorios.

\section{I.5. UN MODELO BASADO EN LA PARTICIPACIÓN DE LOS BENEFICIARIOS Y DE LAS ENTIDADES QUE LES REPRESENTAN}

La participación de los beneficiarios en el SAAD y, en su caso, de sus familias y entidades que les representan constituye uno de los principios que proclama la Ley ${ }^{22}$.

La participación se materializa a través de los órganos consultivos del Sistema y de medidas concretas que favorecen la colaboración de las organizaciones del tercer sector y del voluntariado en la provisión de los servicios.

A la regulación de los órganos consultivos dedica la ley un capítulo específico, dentro del Titulo sobre calidad y eficacia del SAAD ${ }^{23}$. Establece como órganos consultivos los siguientes:

- El Comité Consultivo del Sistema para la Autonomía y Atención a la Dependencia.

- El Consejo Estatal de Personas Mayores.

- El Consejo Nacional de la Discapacidad.

- El Consejo Estatal de Organizaciones no Gubernamentales de Acción Social.

Sus funciones son las de informar, asesorar y formular propuestas sobre materias de especial interés para el funcionamiento de dicho Sistema.

A través del Comité Consultivo del Sistema para la Autonomía y Atención a la Dependencia se hace efectiva, de manera permanente, la participación social e institucional de las organizaciones sindicales y empresariales en el mismo.

La composición del Comité Consultivo tiene carácter tripartito, está integrado por seis representantes de la Administración General del Estado, seis de las administraciones de las Comunidades Autónomas y seis de las Entidades Locales, nueve de las Organizaciones Empresariales y nueve de las Organizaciones Sindicales más representativas. Para la adopción de acuerdos tiene carácter paritario entre Administraciones Públicas por una parte y organizaciones sindicales y empresariales por otra. Sus acuerdos se adoptan por mayoría de los votos emitidos en cada una de las partes, requiriendo,

\footnotetext{
${ }^{22}$ Ley 39/2007, Art. 3 k).

${ }^{23}$ Ley 39/2007, Capítulo V, Título II, artículos 40 y 41.
} 
por tanto, la mayoría de los votos de las Administraciones Públicas y la mayoría de los votos de las organizaciones sindicales y empresariales.

El Comité Consultivo está presidido por el o la titular de la Secretaria de Estado que tenga esta competencia. Su funcionamiento está regulado por el reglamento interno que ha aprobado el propio Comité, en el que de forma más precisa se detallan las materias que han de ser objeto de informe y consulta.

A los Consejos Estatal de Mayores y Nacional de la Discapacidad la ley les atribuye, como órganos de representación de las personas mayores y con discapacidad, sobre las funciones que ya tienen atribuidas en sus respectivas normas de funcionamiento ${ }^{24}$, las de informe, asesoramiento y formulación de propuestas en relación con la promoción de la autonomía y la dependencia.

En el trámite parlamentario se incorpora también como órgano consultivo el Consejo Estatal de Organizaciones no Gubernamentales de Acción Social, en representación del tercer sector, al que el SAAD atribuye una especial atención, mandatando a los poderes públicos para que promuevan la colaboración solidaria de los ciudadanos a través de la participación de las organizaciones de voluntarios y de las entidades del tercer sector ${ }^{25}$.

\section{DESARROLLO DE LA VALORACIÓN DE LA DEPENDENCIA}

Dice la Ley 39/2006 que son titulares de los derechos establecidos en la presente Ley los españoles que cumplan el requisito de encontrarse en situación de dependencia en alguno de los grados establecidos ${ }^{26}$.

El modelo español, como los de seguridad social centroeuropeos y en contraposición a los nórdicos de carácter universal, precisa de una valoración previa que determine la concurrencia de la situación de dependencia. La ley dedica a ello un capítulo especifico sobre la dependencia y su valoración ${ }^{27}$.

La situación de dependencia se clasificará en tres grados:

a) Grado I. Dependencia moderada: cuando la persona necesita ayuda para realizar varias actividades básicas de la vida diaria, al menos

${ }^{24}$ Real Decreto 1865/2004 de 6 de septiembre, por el que se regula el Consejo Nacional de la Discapacidad y Real Decreto 117/2005, de 4 de febrero, por el que se regula el Consejo Estatal de las Personas Mayores.

25 Ley 39/2007, Art. 16.4.

${ }^{26}$ Ley 39/2006. Art. 5.

${ }^{27}$ Ley 39/2006. Art. Título I, capítulo III, Arts. 26 y 27. 
una vez al día o tiene necesidades de apoyo intermitente o limitado para su autonomía personal.

b) Grado II. Dependencia severa: cuando la persona necesita ayuda para realizar varias actividades básicas de la vida diaria dos o tres veces al día, pero no requiere el apoyo permanente de un cuidador o tiene necesidades de apoyo extenso para su autonomía personal.

c) Grado III. Gran dependencia: cuando la persona necesita ayuda para realizar varias actividades básicas de la vida diaria varias veces al día y, por su pérdida total de autonomía física, mental, intelectual o sensorial necesita el apoyo indispensable y continuo de otra persona o tiene necesidades de apoyo generalizado para su autonomía personal.

Cada uno de estos grados de dependencia se clasificarán en dos niveles, en función de la autonomía de las personas y de la intensidad del cuidado que requiere.

El SAAD sigue los mismos criterios de clasificación en tres grados del modelo alemán, aunque incorpora a su vez niveles dentro de cada grado, lo que a efectos prácticos le asemeja al sistema austriaco en el que se reconocen siete niveles de dependencia. La incorporación de niveles dentro de cada grado era obligada, no solo porque permite discriminar mejor, facilitando con ello la valoración, sino también por la aplicación progresiva de la ley que se regula en la disposición final primera, en la que se fija un período de ocho años.

En este modelo de protección tiene especial importancia el baremo que ha de servir para el reconocimiento de la situación de dependencia.

La ley precisa las características que debe reunir el baremo:

a) El baremo tendrá como referencia la Clasificación Internacional de Funcionamiento, la Discapacidad y la Salud (CIF) de la Organización Mundial de la Salud.

b) Establecerá intervalos de puntuación para la determinación de los grados y niveles.

c) Establecerá los criterios objetivos de valoración de la capacidad de la persona para realizar por si misma las distintas actividades de la vida diaria, así como del grado de autonomía de la persona; específicamente valorará la necesidad de apoyo y supervisión para su realización en las personas con discapacidad intelectual o con enfermedad mental.

d) Asimismo, establecerá el protocolo con los procedimientos y técnicas a seguir para la valoración.

e) El baremo ha de ser acordado en el Consejo Territorial del Sistema para la Autonomía y Atención a la Dependencia y aprobado por el Gobierno mediante Real Decreto. 
En cumplimiento de estas disposiciones el Gobierno, previo acuerdo del Consejo Territorial, ha aprobado Real Decreto ${ }^{28}$, que tiene como objeto la aprobación del baremo para la valoración de los grados y niveles de dependencia previstos en el artículo 26 de la Ley 39/2006, de 14 de diciembre y la escala de valoración especifica para las personas menores de 3 años a que se refiere la disposición adicional decimotercera de la citada Ley.

El requisito de encontrarse en situación de dependencia para ser titular de los derechos establecidos en la Ley se determina para las personas mayores de 3 años mediante la aplicación del baremo que se incorpora como Anexo I del citado Real Decreto. Incluye, además del instrumento de valoración de la dependencia, los criterios de aplicación. Para la valoración de los menores de 3 años se aprueba una escala de valoración especifica, que se adjunta como Anexo II del mismo.

Es también objeto de esta norma la homologación a la situación de dependencia de los pensionistas de gran invalidez en su modalidad contributiva y a quienes tengan reconocida la necesidad del concurso de tercera persona para percibir pensiones no contributivas. En el supuesto de las personas que tengan reconocido el complemento de gran invalidez, mediante la aplicación del baremo, se establece el grado y nivel de dependencia de cada persona, garantizando, en todo caso, el Grado I dependencia moderada nivel 1 . Y en lo que se refiere a las personas con discapacidad, que tengan reconocido el complemento de necesidad de tercera persona, según el Anexo 2 del Real Decreto 1971/1999, de 23 de diciembre de Procedimiento para el reconocimiento, declaración y calificación del grado de minusvalía, se establece la aplicación de la siguiente tabla de homologación.
De 15 a 29 puntos
De 30 a 44 puntos
De 45 a 72 puntos

Grado I de dependencia, nivel 2

Grado II de dependencia, nivel 2

Grado III de dependencia, nivel 2

A las personas que tengan reconocida la necesidad de asistencia de tercera persona, en aplicación del baremo del anexo 2 del Real Decreto 1971/1999, de 23 de diciembre, que en el presente Real Decreto se deroga, se les garantiza el pacífico disfrute de todos los efectos jurídicos de dicho reconocimiento, cuando deban acreditar la situación de dependencia ante cualquier Administración o entidad pública o privada. Parece lógico no perjudicar a quienes actualmente tienen esta prestación reconocida.

${ }^{28}$ Real Decreto 504/2007, de 20 de abril, por el que se aprueba el baremo de valoración de la situación de dependencia establecido por la Ley 39/2006, de 14 de diciembre, de Promoción de la Autonomía Personal y Atención a las personas en situación de dependencia. 
Transcurrido el primer año de su aplicación se contempla la realización de una evaluación de los resultados obtenidos que puede dar lugar a la revisión del baremo por el Consejo Territorial del Sistema para la Autonomía Personal y Atención a la Dependencia, con el fin de corregir efectos no previstos en su aplicación.

Se establece, asimismo, que a partir de la aprobación de este Real Decreto la valoración de la necesidad del concurso de otra persona para el reconocimiento de las prestaciones no contributivas de la Seguridad Social y para el disfrute de cualquier beneficio, servicio o ayuda en los que sea necesaria la acreditación de esta situación, se realizará mediante la aplicación del nuevo baremo.

Finalmente, se deroga el Anexo 2 del Real Decreto 1971/1999, de 23 de diciembre, sobre Procedimiento para el reconocimiento, declaración y calificación del grado de minusvalía, sin perjuicio de lo previsto en la disposición adicional primera, apartado 3 .

El baremo de valoración de los grados y niveles de dependencia (BVD), que se aprueba en el Anexo I de esta norma, determina los criterios objetivos para la valoración del grado de autonomía de las personas, en orden a la capacidad para realizar las tareas básicas de la vida diaria, así como la necesidad de apoyo y supervisión a este respecto para personas con discapacidad intelectual o enfermedad mental.

El baremo será único ${ }^{29}$, igual para todas las Comunidades Autónomas. En consecuencia, la valoración realizada tendrá efectos en todo el territorio del Estado.

La protección del Sistema se extiende a quienes, como consecuencia de una valoración previa, son declarados en situación de dependencia por su dificultad para la realización de las actividades básicas de la vida diaria o precisan de apoyo para la promoción de su autonomía personal. Estamos ante un Sistema, en el que la aplicación del baremo tiene como finalidad determinar la eligibilidad de los beneficiarios a las prestaciones de dependencia, siguiendo las pautas de los modelos centroeuropeos de Seguridad Social. En los modelos nórdicos, por el contrario, la valoración que se realiza no tiene como objetivo discriminar quién es o no dependiente, sino cuales son los servicios que necesita.

El Sistema protege no sólo a las personas que necesitan el apoyo de tercera persona para la realización de las actividades básicas de la vida diaria, sino también a quienes necesitan apoyo para la promoción de su autonomía personal, por lo que el baremo debe valorar también a quienes necesitan de estos apoyos. La ley define de forma precisa los conceptos de

${ }^{29}$ Artículo 27. 2. 
dependencia ${ }^{30}$ y autonomía ${ }^{31}$ : durante su tramitación parlamentaria se han aceptado enmiendas que han modificado el ámbito de protección, incorporando la protección de nuevas situaciones, que darán lugar a nuevos beneficiarios no previstos en el proyecto. La modificación más significativa en este sentido se refiere a la ampliación del concepto de dependencia y a la modificación de la conceptualización de los grados que se determinan en el artículo 26 de la ley, en los que se ha incorporado un inciso final en cada uno de ellos, en los que se precisan los apoyos que la persona pueda necesitar para hacer posible su autonomía personal. Varían como es lógico de un grado a otro, desde un apoyo "intermitente o limitado" para el grado I, "extenso" para el grado II e "indispensable, continuo y generalizado" para el grado III. Como puede comprobarse, estamos ante conceptos jurídicos indeterminados, que han tenido una concreción técnica en el baremo al que anteriormente nos referíamos.

De conformidad con el citado Real Decreto el baremo ha de aplicarse ajustándose a criterios específicos de aplicación ${ }^{32}$ :

El baremo concluye con el protocolo de aplicación y la determinación de la severidad de la dependencia con la siguiente escala de puntuación:

\begin{tabular}{|lc|cc|}
\cline { 3 - 4 } \multicolumn{1}{c|}{} & Puntos & & Puntos \\
\hline Grado I & $25-49$ & Nivel 1 & $25-39$ \\
\cline { 3 - 4 } & & Nivel 2 & $40-49$ \\
\hline \multirow{3}{*}{ Grado II } & \multirow{3}{*}{ G0-74 } & Nivel 1 & $50-64$ \\
\cline { 3 - 4 } & \multirow{3}{*}{ Grado III } & Nivel 2 & $65-74$ \\
\cline { 3 - 4 } & \multirow{2}{*}{$75-100$} & Nivel 1 & $75-89$ \\
\cline { 3 - 4 } & & Nivel 2 & $90-100$ \\
\hline
\end{tabular}

30 Ley 39/2007, de 14 de diciembre, de Promoción de la Autonomía Personal y Atención a las personas en situación de dependencia. Art. 2. 2 "Dependencia: el estado de carácter permanente en que se encuentran las personas que, por razones derivadas de la edad, la enfermedad o la discapacidad, y ligadas a la falta o a la pérdida de autonomía física, mental, intelectual o sensorial, precisan de la atención de otra u otras personas o ayudas importantes para realizar actividades básicas de la vida diaria o, en el caso de las personas con discapacidad intelectual o enfermedad mental, de otros apoyos para su autonomía personal.".

31 Art. 2. 1 "Autonomía: la capacidad de controlar, afrontar y tomar, por propia iniciativa, decisiones personales acerca de cómo vivir de acuerdo con las normas y preferencias propias así como de desarrollar las actividades básicas de la vida diaria”.

32 Real Decreto 504/2007, de 20 de abril, por el que se aprueba el baremo de valoración de la situación de dependencia establecido por la Ley 39/2006, de 14 de diciembre, de Promoción de la Autonomía Personal y Atención a las personas en situación de dependencia. Anexo 1 Criterios de aplicación. 


\section{DESARROLLO DEL RÉGIMEN DE PRESTACIONES DE DEPENDENCIA}

La protección que ofrece el SAAD se estructura en tres niveles ${ }^{33}$. En ellos se determina la responsabilidad de la financiación, así como los instrumentos jurídicos que harán posible su aplicación por parte de las Administraciones Públicas, teniendo en cuenta para ello las competencias atribuidas por la Constitución y los Estatutos de Autonomía.

El Real Decreto 614/2007, de 11 de mayo, sobre nivel mínimo de protección del Sistema para la Autonomía y Atención a la Dependencia garantizado por la Administración General del Estado ha desarrollado el primer nivel de protección. A través de este nivel se contribuye a la financiación del SAAD, haciendo posible el acceso a las prestaciones de dependencia en condiciones de igualdad en todo el territorio del Estado.

Por su parte, el Real Decreto 727/2007, de 8 de junio, sobre criterios para determinar las intensidades de protección de los servicios y la cuantía de las prestaciones económicas de la Ley 39/2006, de 14 de diciembre, de Promoción de la Autonomía Personal y Atención a las personas en situación de dependencia, define por su parte el alcance de la protección que constituye el nivel mínimo más el acordado y que, en definitiva, genera el derecho a la promoción de la autonomía y atención a la dependencia que esta ley garantiza a los ciudadanos como derecho subjetivo. Su financiación vendrá determinada por el marco de cooperación interadministrativa acordado y por los convenios de colaboración que se suscriban entre la Administración General del Estado y las correspondientes Comunidades Autónomas ${ }^{34}$.

En el campo de la protección, el Sistema comprende prestaciones de dependencia en dos modalidades, mediante la oferta de un catálogo de servicios, según las necesidades que requiere la persona reconocida como dependiente, o mediante la concesión de prestaciones económicas.

El Catálogo de servicios ${ }^{35}$ ofrece toda la gama de servicios que la geriatría y gerontología recomiendan para la atención de las personas con depen-

\footnotetext{
${ }^{33}$ Ley 39/2006. Art. 7. Niveles de protección del Sistema.

${ }^{34}$ Ley 39/2006. Art. 10.3.

${ }^{35}$ Ley 39/2006. Art. 15
}

a) Los servicios de prevención de las situaciones de dependencia y los de promoción de la autonomía personal.

b) Servicio de Teleasistencia.

c) Servicio de Ayuda a domicilio:

(i) Atención de las necesidades del hogar.

(ii) Cuidados personales. 
dencia. Se ha comentado que el catálogo no es novedoso respecto de los servicios que actualmente se vienen ofreciendo. Considero, sin embargo, que un catálogo de servicios, si se establece por ley, debe ofrecer aquellos servicios que ya tengan acreditado su eficacia, debiendo facilitar, sin necesidad de cambios legislativos, la incorporación de cualquier técnica de atención que la experiencia aconseje introducir.

El Real Decreto 727/2007, de 8 de junio, sobre criterios para determinar las intensidades de protección de los servicios y la cuantía de las prestaciones económicas de la Ley 39/2006, regula el alcance de los servicios del catálogo; su contenido, entre otras materias, desarrolla el artículo 10.3 de la misma, en el que se establece que el Gobierno, mediante Real Decreto, aprobará los criterios establecidos por el Consejo Territorial del Sistema para la Autonomía y Atención a la Dependencia para determinar la intensidad de protección de los servicios y la compatibilidad e incompatibilidad entre los mismos.

Si se analizan con detenimiento los criterios acordados por el Consejo Territorial y aprobados por el Gobierno en el Real Decreto citado, se observan demasiadas cautelas para no ir más allá de lo que la ley establece y no invadir competencias de las Comunidades Autónomas. Estos criterios son una muestra evidente de la dificultad de alcanzar acuerdos en el Consejo Territorial. Se puede decir que estamos ante un acuerdo de mínimos, sin embargo no debe olvidarse que son precisamente estos criterios, sobre las intensidades de protección, lo que garantiza la cohesión del SAAD en todo el territorio del Estado. A pesar del carácter conservador y limitado de los citados criterios, ni siquiera se pudo conseguir la unanimidad de los representantes de las Comunidades Autónomas y de la Administración General de Estado en su aprobación.

En consecuencia, serán las Comunidades Autónomas quienes, en aplicación de la ley y de los criterios aprobados en el Real Decreto citado anteriormente, regulen las intensidades de protección a la que los ciudadanos de cada Comunidad tendrá derecho.

Entre los criterios aprobados y recogidos en el Real Decreto es preciso referenciar:

d) Servicio de Centro de Día y de Noche:

(i) Centro de Día para mayores.

(ii) Centro de Día para menores de 65 años.

(iii) Centro de Día de atención especializada.

(iv) Centro de Noche.

e) Servicio de Atención Residencial:

(i) Residencia de personas mayores en situación de dependencia.

(ii) Centro de atención a personas en situación de dependencia, en razón de los distintos tipos de discapacidad. 
a) La fijación de la intensidad de los servicios se realizará "por el contenido prestacional de cada uno de los servicios asistenciales y por la extensión o duración del mismo según el grado y nivel de dependencia”. ${ }^{36}$

b) La determinación del concepto de servicios asistenciales como objeto de protección del SAAD, en contraposición a los de manutención y alojamiento; se consideran servicios asistenciales "los que ha de recibir la persona dependiente para su atención y cuidado personal en la realización de las actividades de la vida diaria, así como los que tienen como finalidad la promoción de su autonomía personal" 37 .

c) El establecimiento de las intensidades de cada uno de los servicios del catálogo, recurriendo para ello básicamente a reproducir el contenido prestacional ya establecido en la ley. Sólo al determinar la intensidad correspondiente al Servicio de Ayuda a Domicilio se incluyen criterios de extensión o duración, estableciendo el número de horas de atención, mediante la fijación de un intervalo de horas en función de los grados y niveles de dependencia ${ }^{38}$.

Horas de atención

Grado III. Gran Dependencia:

Horas mensuales

Nivel Entre 70 y 90

Nivel 1 Entre 55 y 70

Grado II. Dependencia severa:

Nivel Entre 40 y 55

Nivel 1 Entre 30 y 40

d) Mención especial merecen los criterios sobre la intensidad del Servicio de promoción de la autonomía personal, en tanto que este servicio no se define en la ley 39/2006 y, por tanto requiere de la intervención del Consejo Territorial y del Gobierno. El Real Decreto determina la finalidad del servicio: "desarrollar y mantener la capacidad personal de controlar, afrontar y tomar decisiones acerca de cómo vivir de acuerdo con las normas y preferencias propias y

36 Real Decreto 727/2007, de 8 de junio, sobre criterios para determinar las intensidades de protección de los servicios y la cuantía de las prestaciones económicas de la Ley 39/2006, de 14 de diciembre, de Promoción de la Autonomía Personal y Atención a las personas en situación de dependencia. Art. 4.1.

37 Real Decreto 727/2007, de 8 de junio. Art. 4.2.

38 Real Decreto 727/2007, de 8 de junio. Art. 8 y Anexo I. 
facilitar la ejecución de las actividades básicas de la vida diaria” y se establecen cuales son los servicios de promoción para la autonomía personal: "los de asesoramiento, orientación, asistencia y formación en tecnologías de apoyo y adaptaciones que contribuyan a facilitar la realización de las actividades de la vida diaria, los de habilitación, los de terapia ocupacional así como cualesquiera otros programas de intervención que se establezcan con la misma finalidad." 39

En este servicio se hace una referencia específica a la vinculación de la intensidad del mismo a la existencia o no de recursos asistenciales. La razón ha de buscarse en la dificultad de sustituir estos servicios recurriendo a servicios privados fuera de la Red de servicios del Sistema. No obstante, hay que señalar que es el único servicio en el que se establece esta limitación.

e) Para la determinación de las intensidades se establece que éstas se adecuarán al programa individual de atención y a la normativa específica de las Comunidades Autónomas que, obligatoriamente, habrán de dictar para precisar y hacer efectivos estos criterios.

Se puede decir que en la determinación de los criterios se ha optado por la indefinición sobre el alcance en cuanto a duración o extensión de los servicios de teleasistencia, centros de día y centros residenciales. La Comisión Delegada del Consejo Territorial y las unidades técnicas del Ministerio de Trabajo y Asuntos Sociales renunciaron por su dificultad a una mayor concreción modular en función del grado y nivel, pero sería más justo y equitativo acomodar también la intensidad de estos servicios a módulos prestacionales, en caso contrario podría darse el supuesto de que personas con dependencia de un grado o nivel menor recibieran servicios de mayor intensidad y coste que otras de nivel mayor.

El problema de mayor envergadura al que se enfrenta el Sistema es la insuficiencia de servicios en las distintas Comunidades Autónomas. Es necesario un esfuerzo presupuestario, sostenido en el tiempo, de las Administraciones Públicas que haga posible una ampliación importante de los mismos, haciendo realidad lo establecido en la ley de que las prestaciones económicas de cuidados en el entorno familiar tengan carácter extraordinario. Por otra parte, sólo mediante la puesta a disposición de los ciudadanos de los nuevos servicios se crearán los empleos previstos en el Libro Blanco y en la memoria de la Ley.

$\mathrm{El}$ incremento de la red de centros del Sistema exige la participación no sólo de las administraciones públicas, sino también de la iniciativa privada

39 Real Decreto 727/2007, de 8 de junio. Art.6. 
con y sin fin de lucro. Para ello deberían definirse y establecerse garantías e incentivos adecuados desde la Administración.

También deben establecerse planes de mejora de la Red para que los centros se adecuen en los plazos establecidos a los criterios de acreditación de los centros que está a punto de aprobar el Consejo Territorial.

En relación con las prestaciones económicas, La ley y el Real Decreto las configuran con las siguientes características:

a) La prestación económica vinculada al servicio ${ }^{40}$.

- Se reconoce, en los términos que se establezca, únicamente cuando no sea posible el acceso a un servicio público o concertado de atención y cuidado, en función del grado y nivel de dependencia y de la capacidad económica del beneficiario, de acuerdo con lo previsto en el convenio celebrado entre la Administración General del Estado y la correspondiente Comunidad Autónoma.

- Está, en todo caso, vinculada a la adquisición de un servicio.

- Las Administraciones Públicas competentes deben supervisar, en todo caso, el destino y utilización de estas prestaciones al cumplimiento de la finalidad para la que fueron concedidas.

b) La prestación económica para cuidados en el entorno familiar y apoyo a cuidadores no profesionales ${ }^{41}$.

- Es una prestación de carácter excepcional para cuando el beneficiario esté siendo atendido por su entorno familiar.

- Deben reunirse las condiciones adecuadas de convivencia y de habitabilidad de la vivienda y así lo establezca su Programa Individual de Atención ${ }^{42}$.

- Deben, asimismo, reunirse las condiciones de acceso en función del grado y nivel reconocido a la persona en situación de dependencia.

- El cuidador deberá ajustarse a las normas sobre afiliación, alta y cotización a la Seguridad Social que se establecen en el Real Decreto 615/2007, de 11 de mayo, por el que se regula la Seguridad Social de los cuidadores de las personas en situación de dependencia.

\footnotetext{
${ }^{40}$ Ley 39/2006. Art. 17.

${ }^{41}$ Ley 39/2006. Art. 18.

${ }^{42}$ Ley 39/2006. Art.14.4.
} 
c) La prestación económica de asistencia personal ${ }^{143}$.

- Tiene como finalidad la promoción de la autonomía de las personas con gran dependencia.

- Su objetivo es contribuir a la contratación de una asistencia personal, durante un número de horas, que facilite al beneficiario el acceso a la educación y al trabajo, así como a una vida más autónoma en el ejercicio de las actividades básicas de la vida diaria.

- Deben reunirse las condiciones específicas de acceso que determine el Consejo Territorial del Sistema para la Autonomía y Atención a la Dependencia. Hasta el momento no ha determinado ningún tipo de condiciones especiales.

El destino y finalidad de las prestaciones de dependencia será, en todo caso, la promoción de la autonomía personal y, por otra, la atención a las necesidades de las personas con dificultades para la realización de las actividades básicas de la vida diaria. Por otra parte, y con el fin de garantizar la calidad de los servicios, estos deberán prestarse por las respectivas Comunidades Autónomas en la Red de Servicios Sociales mediante centros y servicios públicos o privados concertados debidamente acreditados.

Los servicios tendrán prioridad sobre las prestaciones económicas ${ }^{44}$ : "Los servicios del Catálogo del artículo 15 tendrán carácter prioritario y se prestarán a través de la oferta pública de la Red de Servicios Sociales por las respectivas Comunidades Autónomas mediante centros y servicios públicos o privados concertados debidamente acreditados".

La prestación económica vinculada, destinada a la cobertura de los gastos del servicio previsto en el Programa Individual de Atención, se concederá únicamente cuando no sea posible el acceso a un servicio público o privado concertado, mientras que con la oferta existente no sea posible dar cobertura a las necesidades de atención. En consecuencia, hasta que la red de servicios esté totalmente implantada en cada Comunidad Autónoma. La calidad del servicio que se preste con esta prestación queda garantizado mediante la exigencia de que la entidad o centro se halle acreditado para ello por la Administración Pública competente.

Por lo que se refiere a la prestación económica para cuidados en el entorno familiar, el Real Decreto 615/2007, de 11 de mayo, por el que se regula

43 Ley 39/2006. Art. 19.

${ }^{44}$ Ley 39/2007, de 14 de diciembre, de Promoción de la Autonomía Personal y Atención a las personas en situación de dependencia. Art. 14. 2. 
la seguridad social de los cuidadores de las personas en situación de dependencia, establece su carácter excepcional; para la que además de exigir los requisitos de condiciones adecuadas de convivencia y de habitabilidad de la vivienda y así lo establezca su Programa Individual de Atención, establece un determinado grado de parentesco: cónyuge o sus parientes por consaguinidad, afinidad o adopción, hasta el tercer grado de parentesco. Se prevén también modalidades especiales de cuidado para quienes tengan dificultades de atención por la menor presencia de recursos públicos o privados acreditados, la despoblación, o circunstancias geográficas.

Características distintas presenta la prestación económica de asistencia personal, en la que, no obstante la declaración genérica de prioridad de los servicios, no se establece ninguna limitación a su concesión salvo que esté prevista en el Programa Individual de Atención.

Especial relevancia, dentro del SAAD, supone la determinación de las cuantías de las prestaciones económicas, cuya finalidad es satisfacer los costes de los servicios a que están destinadas. La Ley en esta materia no establece criterios para su determinación, limitándose a señalar que "La cuantía de las prestaciones económicas, reguladas en los artículos de esta Sección, se acordará por el Consejo Territorial del Sistema para la Autonomía y Atención a la Dependencia, para su aprobación posterior por el Gobierno mediante Real Decreto" ${ }^{45}$. Y que "La capacidad económica del beneficiario se tendrá también en cuenta para la determinación de la cuantía de las prestaciones económicas" ${ }^{46}$.

En cumplimento de ello, el Consejo Territorial ha acordado ya la cuantía de las prestaciones de la gran dependencia para el año 2007 y de la gran dependencia y del Grado II, nivel 2 par el 2008, acuerdos que ha sido aprobados mediante el Real Decreto 727/2007, de 8 de junio y el Real Decreto $7 / 2008$ de 11 de enero.

En relación con la determinación de la cuantía de las prestaciones económicas el Real Decreto 727/2007, de 8 de junio, establece:

a) Que la cuantía de las prestaciones económicas del Sistema para la Autonomía y Atención a la Dependencia se establecerá anualmente por el Gobierno mediante Real Decreto, previo acuerdo del Consejo Territorial, para los grados y niveles con derecho a prestaciones.

b) Que se actualizarán anualmente en función del incremento del IPC.

c) Que el importe de la prestación económica a reconocer a cada beneficiario se determinará aplicando a la cuantía vigente para cada año un coeficiente reductor según su capacidad económica, de acuerdo con lo

\footnotetext{
45 Ley 39/2007, de 14 de diciembre. Art. 20.

46 Ley 39/2007, de 14 de diciembre. Art. 33. 2.
} 
establecido por la Comunidad Autónoma o Administración que, en su caso, tenga la competencia. Para la determinación de este coeficiente se tendrá en consideración lo que se acuerde por el Consejo Territorial del Sistema para la Autonomía y Atención a la Dependencia.

d) Que en los supuestos en que el beneficiario sea titular de cualquier otra prestación de análoga naturaleza y finalidad, establecida en otro régimen público de protección social, estas se deducirán del importe a reconocer. Se citan específicamente las de Seguridad Social y de la LISMI: El complemento de gran invalidez, el complemento de la asignación económica por hijo a cargo mayor de 18 años con un grado de minusvalía igual o superior al 75 por ciento, el complemento por necesidad de tercera persona de la pensión de invalidez no contributiva y el subsidio de ayuda a tercera persona ${ }^{47}$.

Las cuantías de las prestaciones económicas para los grados III y II durante el ejercicio 2008 son las siguientes:

\begin{tabular}{|c|c|c|c|c|}
\hline Grados y niveles & $\begin{array}{c}\text { Prestaciones } \\
\text { económicas: } \\
\text { vinculada al } \\
\text { servicio } \\
\text { y de asistencia } \\
\text { personal } \\
€ \text { mensuales }\end{array}$ & $\begin{array}{c}\text { Prestación } \\
\text { económica } \\
\text { vinculada al } \\
\text { servicio } \\
\text { anuales }\end{array}$ & $\begin{array}{c}\text { Prestación } \\
\text { económica para } \\
\text { cuidados en el } \\
\text { entorno } \\
\text { familiar } \\
€ \text { mensuales }\end{array}$ & $\begin{array}{c}\text { Prestación } \\
\text { económica para } \\
\text { cuidados en el } \\
\text { entorno } \\
\text { familiar } \\
€ \text { anuales }\end{array}$ \\
\hline Grado III. Nivel 2 & 811,98 & $9.743,76$ & 506,96 & $6.083,52$ \\
\hline Grado III. Nivel 1 & 608,98 & $7.307,76$ & 405,99 & $4.871,88$ \\
\hline Grado II. Nivel 2 $*$ & 450 & 5.400 & 328 & $3.936,00$ \\
\hline
\end{tabular}

* La prestación económica de asistencia personal solo puede ser reconocida apersonas con Grado III.

Por lo que se refiere a la suficiencia de estas cuantías para hacer frente a los costes de los servicios, especialmente los de atención residencial, sería necesario analizar de forma individual la capacidad económica de los beneficiario y la forma en que se determine su participación en los costes. Ahora bien, si tenemos en cuenta las pensiones medias de la Seguridad Social con las cuantías de las prestaciones económicas de la dependencia, se puede decir que este nuevo Sistema de protección proporciona a quienes no puedan ser atendidos en la red de centros y servicios una contribución económica importante para la atención en centros privados. En cualquier caso, el Sistema debe garantizar en todo caso el servicio a quienes carezcan de recursos.

${ }^{47}$ Real Decreto 727/2007, de 8 de junio, arts. 13 y 14 . 


\section{DESARROLLO DE LOS ASPECTOS RELACIONADOS CON LA FINANCIACIÓN}

La Ley establece, en su exposición de motivos, como principios básicos de la financiación del SAAD los de estabilidad, suficiencia y sostenibili$\mathrm{dad}^{48}$. Asimismo, se determina la equidad en la participación de los beneficiarios en el coste de los servicios y la corresponsabilidad en la financiación de las Administraciones.

Sigue en ello las recomendaciones de la Comisión y el Consejo de la Unión Europea sobre los objetivos que deben seguir los Estados en los sistema de protección que promuevan: Accesibilidad de todos los ciudadanos a las prestaciones y servicios sociosanitarios, con independencia de los ingresos o el patrimonio, calidad de la asistencia y sostenibilidad económica del mismo $^{49}$.

La ley garantiza la estabilidad financiera del Sistema desde el momento en que reconoce a las prestaciones de dependencia la naturaleza de derecho subjetivo, que los ciudadanos pueden ejercer frente a las Administraciones Públicas. Anualmente los Presupuestos Generales del Estado y los de las Comunidades Autónomas deberán contemplar los créditos correspondientes. La cofinanciación del beneficiario no afecta a la estabilidad del sistema en cuanto que su aportación estará vinculada a su capacidad económica

La suficiencia financiera se garantiza de forma precisa en la propia ley cuando establece que "La financiación del Sistema será la suficiente para garantizar el cumplimiento de las obligaciones que correspondan a las Administraciones Públicas competentes y se determinará anualmente en los correspondientes Presupuestos" 50 . Estamos ante un mandato a las Administraciones Públicas para que proporcionen, a través de los correspondientes presupuestos, los créditos que sean necesarios para hacer frente a los servicios y prestaciones económicas que se establezcan en desarrollo de la Ley de Promoción de la Autonomía Personal y Atención a las personas en situación de dependencia. No cabe prever situaciones en las que una persona haya sido reconocida como dependiente y no reciba prestaciones por insuficiencia de financiación. Las Administraciones deberán contemplar, en la parte que a cada una le corresponda, la previsión de créditos ampliables para satisfacer los servicios o prestaciones que se contemplen en los correspondientes programas individuales de atención.

\footnotetext{
${ }^{48}$ Ley 39/2007, de 14 de diciembre, Exposición de motivos, 3.

49 Informe conjunto de la Comisión y del Consejo europeos "Apoyar las estrategias nacionales para el futuro de la asistencia sanitaria y los cuidados a las personas mayores", 2003.

${ }^{50}$ Ley 39/2007, de 14 de diciembre. Art. 32.1.
} 
El sistema de financiación está vinculado al régimen impositivo general del Estado y a sus presupuestos de gasto, por lo que cabe decir que estamos ante un modelo financiero clásico, el comúnmente utilizado para hacer frente a las obligaciones del Estado para con sus ciudadanos. Por lo tanto, cabe predicar de él el principio de sostenible en el tiempo.

El concepto de sostenibilidad se predica de aquellos sistemas que permiten ajustar fácilmente los ingresos a los gastos sin generar problemas a la economía en su conjunto o sectores concretos de la misma. Se dice que un Sistema de Seguridad Social es sostenible cuando las cotizaciones se ajustan a los costes de las prestaciones sin ocasionar desequilibrios para la economía del país.

El SAAD tal y como se regula en la Ley y en los Reales Decretos de desarrollo sobre valoración e intensidades y cuantías de las prestaciones, cuando se aplique en su totalidad, supone, según los estudios de coste realizados y las memorias económicas de las citadas normas, unas necesidades financieras en torno a un punto del PIB, que fácilmente puede ser asumido por la economía española con crecimientos como los de los últimos años. Por otra parte, es un hecho el desequilibrio en gasto social de España respecto de la media de los países de la Unión Europea; proyectos como este contribuirán a reducir la distancia, sin efectos significativos para el sistema impositivo.

\section{IV.1. FinANCIACiÓN DEL NIVEL MÍNIMO GARANTIZADO POR la Administración General del Estado}

La financiación del SAAD se fundamenta en los niveles de protección que la Ley establece: El nivel mínimo establecido por la Administración General del Estado, el nivel que se acuerde entre la Administración General del Estado y la Administración de cada una de las Comunidades Autónomas y el nivel adicional que pueda establecer cada Comunidad Autónoma.

La primera pregunta que hemos de formularnos es la del por qué esta distribución de la protección en tres niveles. ¿No hubiera sido más fácil un único sistema de protección que pudiera ser mejorado por las Comunidades Autónomas?

La razón de los tres niveles de protección, entiendo que hay que buscarla en el título competencial en que se fundamenta la intervención del Estado para regular esta materia. El uso del artículo 1491.1 . $^{a}$ de la Constitución, que atribuye la competencia exclusiva del Estado para regular las condiciones básicas que garanticen la igualdad de todos los españoles en el ejercicio de los derechos, conlleva la obligación del Estado de asumir compromisos que hagan posible la igualdad que se pretende establecer. Es precisamente el 
establecimiento de este nivel mínimo, financiado y garantizado por la Administración General del Estado, lo que hace que la Ley sea plenamente constitucional.

Por otra parte, el principio de lealtad constitucional entre las Administraciones Públicas exige que la regulación del Estado no comprometa los recursos financieros de las Comunidades Autónomas, por lo que la protección a través de niveles permite la no interferencia entre las administraciones, al mismo tiempo que favorece la cooperación y una mejor protección de los ciudadanos.

El nivel mínimo de protección a que se refiere el artículo 9 de la Ley 39/2006, con la publicación del Real Decreto 614/2007, de 11 de mayo, sobre nivel mínimo de protección del Sistema para la Autonomía y Atención a la Dependencia, se configura como una aportación de carácter exclusivamente financiero y no de servicios o prestaciones concretas. En el citado Real Decreto se determina que el nivel mínimo de protección de la situación de dependencia "se garantiza mediante la fijación de una cantidad económica que la Administración General del Estado aporta a la financiación del Sistema por cada uno de los beneficiarios reconocidos como dependientes según su grado y nivel, para las prestaciones de dependencia previstas en su programa individual de atención" ${ }^{51}$.

Podría haberse optado por una interpretación más literal del término "mínimo de protección garantizado", entendiendo que la Administración General del Estado debía definir qué servicios de los establecidos en el catálogo o que prestaciones económicas consideraba como mínimo garantizado. Esto es lo que parece desprenderse de la lectura de la Ley, sin embargo hubiera sido excesivamente complejo para la Administración General del Estado entrar a definir servicios para cada grado y nivel y que al mismo tiempo se ajustarán a las previsiones financieras de los Presupuestos Generales. Por otra parte, hubiera podido producirse una ingerencia en las competencias de las Comunidades Autónomas si desde el Gobierno se hubieran definido servicios concretos sin tener en cuenta las necesidades concretas de cada beneficiario que se determinarán en el programa individual de atención.

Según lo establecido en el citado Real Decreto el nivel mínimo será el equivalente a la cantidad fijada para cada grado y nivel de dependencia que se determine anualmente según el calendario de aplicación progresiva establecido en la disposición adicional primera de la Ley.

Para el ejercicio 2008 se establecen las siguientes cantidades:

51 Real Decreto 614/2007, de 11 de mayo, sobre nivel mínimo de protección del Sistema para la Autonomía y Atención a la Dependencia, Art. 3. 
- Grado III Gran Dependencia. Nivel 2

$258,75 €$ mensuales

- Grado III Gran Dependencia. Nivel 1 $175,95 €$ mensuales

- Grado II Dependencia severa Nivel 2 $100,00 €$ mensuales

Estas cuantías serán objeto de revisión anual, mediante real decreto, teniendo en cuenta la actualización aplicada al Indicador Público de Renta de Efectos Múltiples (IPREM).

La financiación de este nivel se establece anualmente en los Presupuestos Generales del Estado, correspondiendo al Gobierno la fijación de la cuantía anual para cada grado y nivel ${ }^{52}$. El Real Decreto determina, asímismo, la forma de pago "La Administración General del Estado hará efectiva a las Comunidades Autónomas las cantidades que procedan en función del número de beneficiarios reconocidos en situación de dependencia con derecho a prestaciones, teniendo en cuenta para ello su grado y nivel y la fecha de efectividad de su reconocimiento. Los créditos necesarios para esta finalidad se librarán mensualmente por doceavas partes, según el número de beneficiarios con derecho a prestación, procediéndose a su regularización con carácter trimestral. Para ello, las Comunidades Autónomas informarán a la Administración General del Estado de las resoluciones de reconocimiento adoptadas, así como del grado y nivel de los beneficiarios, a través de la conexión a la red de comunicaciones y servicios telemáticos del Sistema”.

Respecto de la suficiencia de las cuantías establecidas para el nivel mínimo, seguramente desde las Comunidades Autónomas se considerará que las cantidades citadas son insuficientes, puesto que su participación en la financiación será mayor o menor en función de cual sea la aportación del Estado. Por el contrario, desde la Administración General del Estado se considerarán suficientes, puesto que, si el nivel mínimo fuese más elevado, el compromiso financiero de las Comunidades Autónomas en el nivel acordado se reduciría, cuando son las Comunidades Autónomas quienes tienen la competencia plena en esta materia.

El presupuesto distribuido entre las Comunidades Autónomas por el IMSERSO en concepto de mínimo garantizado por beneficiarios reconocidos con derecho a prestación ha sido de 82.563.029 € en el ejercicio 2007 y $502.353 .576 €$ en el 2008 .

\section{IV.2. LA FINANCIACIÓN DEL NIVEL ACORDADO ENTRE LA ADMINISTRACIÓN General del Estado y las Comunidades Autónomas}

El 2. ${ }^{\circ}$ nivel de protección es el que se acuerda entre la Administración General del Estado y la Administración de cada una de las Comunidades

52 Ley 39/2007, de 14 de diciembre. Art. 9 y Disposición adicional Primera. Real Decreto 614/2007, de 11 de mayo, Art. 3. 
Autónomas y su financiación se lleva a cabo a través de los correspondientes convenios, previo acuerdo del marco de cooperación en el seno del Consejo Territorial ${ }^{53}$.

La ley determina cuál debe ser la participación mínima de cada una de las Comunidades Autónomas cuando establece que la aportación de la Comunidad Autónoma será, para cada año, al menos igual a la que realice la Administración General del Estado en el nivel mínimo más el acordado ${ }^{54}$.

La financiación de este nivel por parte de la Administración General del Estado estará condicionada por dos factores, en primer lugar por la cantidad que para este nivel se establezca en los presupuestos generales del Estado y por otra por la cantidad que cada Comunidad aporte para la financiación de la dependencia.

La distribución de la cantidad presupuestada para el nivel acordado dice la ley que se repartirá entre las Comunidades Autónomas teniendo en cuenta los criterios de la población dependiente, la dispersión geográfica, la insularidad, los emigrantes retornados y otros factores; señalando que podrán ser revisados por las partes.

El Consejo en cumplimiento de este mandato ha concretado los criterios a que se refiere la ley, especialmente los otros factores, habiendo ya establecido para los ejercicios 2007 y 2008 criterios de distribución, asi como la ponderación de los mismos ${ }^{55}$ :

- Población dependiente.

- Dispersión geográfica.

- Insularidad.

- Emigrantes retornados

- Otros factores: Renta per cápita y pensión media de jubilación de la Comunidad.

53 Ley 39/2007, de 14 de diciembre. Art. 7 y 10.

${ }^{54}$ Ley 39/2007, de 14 de diciembre. Art. 32.3.

55 Resolución de 23 de mayo de 2007, del Instituto de Mayores y Servicios Sociales, por la que se publica el Acuerdo de Consejo de Ministros, por el que se aprueba el marco de cooperación interadministrativa y criterios de reparto de créditos de la Administración General del Estado para la financiación del nivel acordado, previsto en la Ley 39/2006, de 14 de diciembre, de Promoción de la Autonomía Personal y Atención a las personas en situación de dependencia.

Resolución de 8 de agosto de 2008, del Instituto de Mayores y Servicios Sociales, por la que se publica el Acuerdo de Consejo de Ministros, en su reunión del día 1de agosto de 2008, por el que se aprueba el marco de cooperación interadministrativa y criterios de reparto de créditos de la Administración General del Estado para la financiación durante 2008 del nivel acordado, previsto en la Ley 39/2006, de 14 de diciembre, de Promoción de la Autonomía Personal y Atención a las Personas en Situación de Dependencia. 
Para la ponderación de estos criterios el Consejo territorial ha acordado utilizar como referencia las ponderaciones de la Ley 21/2001, por la que se regulan las medidas fiscales y administrativas del nuevo sistema de financiación de las Comunidades Autónomas de régimen común y Ciudades con Estatuto de Autonomía, adecuándolas a las peculiaridades de la Ley $39 / 2006$.

Teniendo en cuenta los citados antecedentes legales, la financiación del nivel acordado del Sistema para la Autonomía Personal y Atención a la Dependencia se realiza para el ejercicio 2007 del siguiente modo:

- Población dependiente estimada, 94\%

- Dispersión, $1,2 \%$

- Insularidad, 0,6\%

- Emigrantes retornados, 0,2\%

- Superficie, $4 \%$

Asimismo y con el fin de compensar los déficits de financiación que puedan derivarse de la participación de los beneficiarios en el coste de los servicios se crea un fondo adicional.

Su distribución se realiza en función de la renta per cápita disponible de los hogares, en referencia a la población dependiente en grado III menor de 65 años de cada Comunidad Autónoma, y en función de la pensión media de jubilación, en referencia a la población dependiente en grado III mayor de 65 años de cada Comunidad Autónoma.

El crédito de la Administración General del Estado para el nivel acordado distribuido en base a los anteriores criterios ha sido de 220 millones de en el ejercicio 2007 y 241 millones en el 2008.

\section{IV.3. DETERMINACIÓN DE LA CAPACIDAD ECONÓMICA Y PARTICIPACIÓN DE LOS BENEFICIARIOS EN EL COSTE DE LOS SERVICIOS Y PRESTACIONES}

El tercer cauce de financiación, además de la Administración del Estado y de las Comunidades Autónomas es el que se refiere a la participación de los beneficiarios. La Ley establece que los beneficiarios de prestaciones de dependencia participarán en la financiación de las mismas, según el tipo y coste del servicio y de su capacidad económica personal, de acuerdo con los criterios que se establezcan por el Consejo Territorial del SAAD. Asimismo establece que la capacidad económica del beneficiario se determinará, en la forma que reglamentariamente se establezca, a propuesta de este órgano ${ }^{56}$.

\footnotetext{
${ }^{56}$ Ley 39/2007, de 14 de diciembre. Art. 33.
} 
Es preciso, por tanto, que el Consejo Territorial se manifieste mediante un acuerdo cuyo objeto sea la determinación de la capacidad económica de los beneficiarios y establecimiento de los criterios mínimos comunes de su participación económica en las prestaciones del Sistema, sin perjuicio de que las Comunidades Autónomas o Administración competente puedan regular condiciones mas ventajosas.

La Comisión Delegada del Consejo ha trabajado desde la aprobación de la Ley en llegar a u acuerdo satisfactorio para todos, en el que, por una parte, se establecieran criterios comunes precisos que garantizan la homogeneidad de la cofinanciación del beneficiario en todo el territorio nacional y, por otra, se respetara la competencia de las Comunidades Autónomas en la regulación de esta materia. A la fecha de redacción de este capítulo, existe un acuerdo aprobado en el Consejo Territorial del Sistema con fecha 27 de noviembre de 2008. Algunas Comunidades se han abstenido por razones que tienen más que ver con el efecto que su aprobación tiene sobre el reparto de la financiación entre el Estado y las Comunidades y sobre a quién le corresponde convertir esta Acuerdo en norma que sobre el contenido del mismo.

El Acuerdo contiene dos partes, que podían haber constituido acuerdos diferenciados, no obstante por su interrelación se acordó que formaran parte de un único acuerdo: La propuesta de determinación de la capacidad económica del beneficiario y los criterios de participación económica del beneficiario en las prestaciones del SAAD.

\section{a) La determinación de la capacidad económica}

La capacidad económica personal de los beneficiarios, de conformidad con lo establecido en la Ley se determinará en atención a la renta y al patrimonio del beneficiario ${ }^{57}$.

Por lo tanto la primera cuestión que aborda el Acuerdo es qué se entiende por renta y por patrimonio a los efectos de esta Ley.

Se entiende por renta el concepto establecido en la regulación del impuesto sobre la renta de las personas físicas con algunas excepciones y matizaciones. Así se considera renta "los ingresos del beneficiario, derivados tanto del trabajo como del capital, así como cualesquiera otros sustitutivos de aquellos, atendiendo a la Ley 35/2006, de 28 de noviembre, del Impuesto sobre la Renta de las Personas Físicas y de modificación parcial de las leyes de los impuestos sobre Sociedades, sobre la Renta de no Residentes y sobre el Patrimonio, o, en su caso, a las normas fiscales que pudieran ser de aplicación”.

${ }^{57}$ Ley 39/2007, de 14 de diciembre. Art. 14.7. 
En los ingresos del beneficiario no se tendrán en consideración como renta la cuantía de las prestaciones de análoga naturaleza y finalidad recogidas en el artículo 31 de la Ley 39/2006, de 14 de diciembre.

Se plantean dudas en relación con otros ingresos exentos en la determinación de la base imponible del impuesto, como son las prestaciones de incapacidad permanente absoluta o los premios de sorteos de la lotería nacional. Mi criterio es que en aras de la equidad deben computar de igual forma en que lo hacen las pensiones de jubilación.

Asimismo, se ha dejado pendiente a regulación del Ministerio de Economía y Hacienda si las rentas derivadas de los seguros privados de dependencia, a que se refiere el artículo 51.5 de la Ley 35/2006, de 28 de noviembre, del Impuesto sobre la Renta de las Personas Físicas y de modificación parcial de las leyes de los Impuestos sobre Sociedades, sobre la Renta de no Residentes y sobre el Patrimonio, han de formar o no parte de la capacidad económica del beneficiario.

Por lo que se refiere al patrimonio del beneficiario, se considera que forma parte del patrimonio "el conjunto de bienes y derechos de contenido económico de que sea titular, con deducción de las cargas y gravámenes que disminuyan su valor, así como de las deudas y obligaciones personales de las que deba responder, de conformidad con las normas fiscales que, en su caso, pudieran resultar de aplicación". No se incluye ninguna referencia a la Ley del impuesto sobre el patrimonio al encontrarse en trámite de derogación este impuesto en la Cortes.

Sobre si la vivienda habitual debía o no formar parte del cómputo de la capacidad económica se ha producido un intenso debate en la sociedad. Los Interlocutores Sociales se han manifestado en contra de que computase en cualquiera de los supuestos. Las organizaciones de mayores y de personas con discapacidad han manifestado también su preocupación por el tratamiento que el Acuerdo diera a este asunto. El Consejo Territorial, yo creo que acertadamente, ha acordado que la vivienda habitual sólo compute en el supuesto de que el beneficiario perciba el servicio de Atención Residencial o la prestación económica vinculada a tal servicio y no tenga personas a su cargo que continúen residiendo en dicha vivienda. Es un hecho que existen diferencias importantes en los servicios que conlleva la atención residencial respecto de el centro de día o la ayuda a domicilio. En el primero servicio todas las necesidades que requiere el beneficiario sanitarias, de cuidado asistencial durante las veinticuatro horas del día, así como las de alojamiento y manutención están cubiertas, sin embargo quienes son atendidos en los demás servicios deben hacer frente con sus propios recursos a lsa necesidades no cubiertos por el servicio, entre las que se encuentran las del alojamiento y manutención. 
Parece lógico que se establezca un tratamiento diferenciado en estos distintos supuestos.

Determina lo que debe entenderse como personas a su cargo, considerando como tales "el cónyuge o pareja de hecho, ascendientes mayores de 65 años, descendientes o personas vinculadas al beneficiario por razón de tutuela y/o acogimiento menores de 25 años o mayores de tal edad en situación de dependencia o con discapacidad, siempre que convivieran con el beneficiario y dependan económicamente del mismo".

En los supuestos de cotitularidad, como parece lógico, sólo se computa el porcentaje correspondiente a la propiedad del beneficiario.

"No se computarán en la determinación del patrimonio los bienes y derechos aportados a un patrimonio especialmente protegido de los regulados por la Ley 41/2003, de 18 de noviembre, de protección patrimonial de las personas con discapacidad y de modificación del Código Civil, de la Ley de Enjuiciamiento Civil y de la Normativa Tributaria con esta finalidad, del que sea titular el beneficiario, mientras persista tal afección”. Esta medida es coherente con los fines del patrimonio protegido. No sería procedente establecer medidas tendentes a que las personas con discapacidad y sus familias creen patrimonios de esta naturaleza con el fin de garantizar la atención en un futuro y que al mismo tiempo se graven computando a los efectos de determinar la cofinanciación. No obstante, y en coherencia si computan las rentas derivadas de dicho patrimonio, cuando no se integren en el mismo y se destinen a cualquier otro fin.

De especial interés es la forma en que computa el patrimonio en la determinación de la capacidad económica. El Acuerdo establece que est computa, incrementando la renta con un porcentaje aplicado al valor patrimonio neto, que varia en función de la edad del beneficiario, dando con ello cumplimiento al mandato de la Ley de que en la consideración del patrimonio se tendrá en cuenta la edad del beneficiario. Los porcentajes establecidos son los siguientes: Un 5 por ciento a partir de los 65 años de edad, un 3 por ciento de los 35 a los 65 años y de un 1 por ciento a los menores de 35 años.

Recoge, asimismo, el Acuerdo, que computarán en la determinación de la capacidad económica las disposiciones patrimoniales realizadas por el beneficiario en los cuatro años anteriores a la presentación de la solicitud de prestaciones del Sistema, en los términos recogidos en la Disposición Adicional Quinta de la Ley 41/2007, de 7 de diciembre, por la que se modifica la ley 2/1981, de 25 de marzo, de regulación del Mercado Hipotecario y otras normas del sistema hipotecario y financiero, de regulación de las hipotecas inversas y el seguro de dependencia y por la que se establece determinada norma tributaria. 


\section{b) Criterios de participación económica del beneficiario en las prestaciones $\operatorname{del} S A A D$}

La Ley establece que el beneficiario participará en la financiación de las prestaciones según el tipo y coste del servicio y su capacidad económica personal ${ }^{58}$. En aplicación de este mandato el Acuerdo establece criterios deferentes según se trate de servios del catálogo o de prestaciones económicas y dentro de estas dos modalidades distingue entre servicios de atención residencial y otros servicios.

En cumplimiento del mandato de la Ley consagra la garantía de atención a quienes carezcan de recursos económicos, que se establece para quienes reciben atención en su domicilio en tener ingresos inferiores a un IPREM. Para quienes reciban atención residencial en la cantidad que las Comunidades Autónomas establezcan como cantidad garantizada a los beneficiarios para gastos personales.

La Ley asimismo mandata que "para fijar la participación del beneficiario se tendrá en cuenta la distinción entre servicios asistenciales y de manutención y hoteleros" ${ }^{59}$. Sobre esta materia el Acuerdo se limita a señalar que se tendrá en cuenta y que deberán ser asumidos por el beneficiario, en parte o en su integridad, cuando cuente con capacidad económica suficiente para ello, dejando que sea la Comunidad Autónoma quien fije o no tablas específicas.

La determinación concreta de la participación del beneficiario le corresponde a la Comunidad Autónoma o Administración que, en su caso, tenga la competencia, quien establecerá la tabla de participación concreta para cada servicio según la capacidad económica del beneficiario. Su determinación exacta se realizará mediante la aplicación de una fórmula matemática que garantice la equidad en la progresividad de la participación.

La cofinanciación del beneficiario tiene como ejes fundamentales el coste del servicio, que deberá establecerse para cada servicio por la Comunidad Autónoma mediante la fijación de un Indicador de Referencia, y la capacidad económica del beneficiario, sobre la cual se aplicará el porcentaje que en cada supuesto corresponda.

El Indicador de Referencia de los servicios de atención residencial y de centros de día estará en relación con el precio de concertación de plazas en centros de iniciativa privada. de la Ayuda Domicilio, el indicador se fijará en función del tipo de servicio y de la intensidad respecto del cual se calculará la aportación del beneficiario.

\footnotetext{
58 Ley 39/2007, de 14 de diciembre. Art. 33.1.

59 Ley 39/2007, de 14 de diciembre. Art. 33.3.
} 
La participación del beneficiario en el servicio de atención residencial se establecerá mediante la aplicación de un porcentaje en función de su capacidad económica, que estará comprendido entre el 70 y el 90 por ciento de la misma, aplicados estos porcentajes de forma progresiva. En ningún caso esta participación superará el 90 por ciento del indicador de referencia.

Por lo que se refiere a los servicios de Centros de Día y Ayuda a domicilio la participación del beneficiario se establecerá en un porcentaje de su capacidad económica, comprendido entre el 10 y el 65 por ciento, sin que esta participación supere el 65 por ciento del indicador de referencia. Podrá este porcentaje incrementarse si el servicio de Centro de Día o de Noche conlleva transporte y/o manutención.

Fija también el Acuerdo el destino de las prestaciones que perciba el beneficiario de análoga naturaleza y finalidad del artículo 31 de la Ley 39/2006, señalando que deberá ser destinada a la financiación del coste del servicio sin que en ningún caso la participación del beneficiario supere el precio de referencia del servicio que recibe.

Por lo que se refiere a la participación del beneficiario en el coste de las prestaciones económicas que manda la Ley 59, la técnica que se incorpora al acuerdo es la establecida en el Real Decreto Real Decreto 727/2007, de 8 de junio y en la regulación utilizada por algunas Comunidades Autónomas sobre esta materia, reducir la cuantía de la prestación de forma progresiva en función de la capacidad económica hasta un límite porcentual.

"Si la capacidad económica del beneficiario es igual o inferior al IPREM, la cuantía de prestación será del 100 por 100 de la cantidad establecida para cada una de las prestaciones en el Real Decreto anual de cuantías.

Si la capacidad económica es superior al IPREM, la Comunidad Autónoma o Administración que, en su caso, tenga la competencia establecerá los índices de reducción aplicables, sin que en ningún caso la cantidad resultante pueda ser inferior al 40 por ciento de la cuantía establecida anualmente para las prestaciones económicas vinculada al servicio y de asistencia personal y del 75 por ciento para la de cuidados en el entorno familiar, salvo que se haya reconocido algún tipo de compatibilidad con los servicios del Catálogo".

Se establecen asimismo cautelas respecto a las prestaciones de análoga naturaleza y específicamente respecto de la cuantía de la prestación económica vinculada y de asistencia personal que no podrá en ningún caso ser superior a la aportación del beneficiario por el coste del servicio que recibe asi como la obligación del beneficiario de realizar un gasto igual o superior a la cuantía máxima establecida para dichas prestaciones.

Finalmente el Acuerdo prevé la situación de las personas en situación de dependencia que a la fecha de aprobación del mismo estén atendidas en 
centros públicos o concertados. Para estos casos, comtempla el mantenimiento del régimen de participación que les fuera de aplicación, salvo que la nueva regulación les fuera más favorable o específicamente considere y regule esta situación.

\section{BIBLIOGRAFÍA}

Atención a las personas en situación de dependencia en España: Libro Blanco: diciembre 2004. Madrid: Instituto de Mayores y Servicios Sociales, 2005. 820 p.

Barcelón Cobedo, Susana; Quintero Lima, María Gema. Las situaciones de dependencia personal como nueva contingencia protegida por el sistema de protección social. Revista del Ministerio de Trabajo y Asuntos Sociales. 2006, n. 60, p. 13-33.

Baviera Puig, Inmaculada. La protección de la dependencia: un estudio global: claves para su aplicación y desarrollo legislativo. Cizur Menor (Navarra): Thomson Aranzadi, 2007. 235 p.

CASAdo, Demetrio.- Expectativas de las personas mayores respecto a la Ley de dependencia. Revista del Ministerio de Trabajo y Asuntos Sociales. 2006, n. 60, p. 149-165.

Сово Gálvez, Pablo. La atención a las personas en situación de dependencia. Los Derechos de las personas con discapacidad. 2007. Volumen I Aspectos jurídicos. p. 841846. ISBN 978-84-96518-90-2.

Coвo Gálvez, Pablo.. Minusval Un nuevo sistema de protección social.

Сово Gálvez, Pablo. Claridad. Revista de UGT. N. ${ }^{\circ}$ 5. 2006. El Libro Blanco. Conceptualización de la dependencia y su impacto sobre la población a protegerl IMSERSO y Coordinador del Libro Blanco.

Сово Gálvez, Pablo: La Ley de promoción de la autonomía personal y atención a las personas en situación de dependencia al año de su aplicación. Sobre ruedas, ISSN 0214-2163, N. ${ }^{\circ}$ 69, 2008, pags. 10-11.

Сово GÁlvez, Pablo. La ley de promoción de la autonomía personal y atención a las personas en situación de dependencia y su impacto sobre la asistencia sanitaria pública. DS: Derecho y salud, ISSN 1133-7400, Vol. 15, N. ${ }^{\circ}$ 1, 2007 (Ejemplar dedicado a: XV Congreso "Derecho y Salud"), pags. 63-76.

Comisión Europea. Frente a los cambios demográficos, una nueva solidaridad entre generaciones: libro verde. Luxemburgo: Oficina de Publicaciones Oficiales de las Comunidades Europeas, 2005. 29 p.

Consejo Económico y Social (España). Dictámenes 2006. Madrid: Consejo Económico y Social, Departamento de Publicaciones, 2006. 250 p.

Cuidados a las personas mayores en los hogares españoles: el entorno familiar. Madrid: IMSERSO, 2005. 256 p.

DeAn, Malcolm. Envejecer en el siglo XXI. Boletín sobre el envejecimiento. 2006, n. 21, p. $1-48$

Edad \& Vida. Posicionamiento de Edad \& Vida sobre la conversión de activos inmobiliarios en renta: la vivienda como factor de mejora de la calidad de vida de las personas mayores: operaciones de transformación de propiedad inmobiliaria en liquidez. Madrid: Edad \& Vida, 2005? 24 p. 
Garcia Herrero, Gustavo. Los servicios sociales y la Ley de promoción de la autonomía personal y atención a las personas en situación de dependencia. Trabajo social hoy. 2006, n. 48, p. 63-95

IgLesias, Pilar. Sistema nacional de dependencia. Revista del Ministerio de Trabajo y Asuntos Sociales. 2006, n. 60, p. 87-92

Herce, José A.; et al. El Sistema Nacional de Dependencia, evaluación de sus efectos sobre el empleo. Revista del Ministerio de Trabajo y Asuntos Sociales. 2006, n. 60, p. 167195

Jornada Aportaciones de la Psicología para la Promoción de la Autonomía Personal y Atención a las personas en situación de dependencia (2006Madrid). Jornada Aportaciones de la Psicología para la Promoción de la Autonomía personal y Atención a las Personasen Situación de Dependencia, 17 de octubre de 2006 [Recurso electrónico]. Madrid: IMSERSO: Colegio Oficial de Psicólogos de Madrid, 2006.

López i Casasnovas, Guillem; et al Envejecimiento y dependencia, situación actual y retos de futuro. Barcelona: Caixa Catalunya, 2005. 90 p.

Minusval. 2007, n. 161, p. 11-58 DEPENDENCIA, un nuevo derecho: dossier

Navarro Garzón, Micaela. Atención a las situaciones de dependencia en Andalucía: una visión panorámica. Revista del Ministerio de Trabajo y Asuntos Sociales. 2006, n. 60, p. 93-105

Observatorio de Personas Mayores (España). Presente y futuro del cuidado de dependientes en España y Alemania. Boletín sobre el envejecimiento. 2005, n. 16, p. 1-36

Rodríguez Cabrero, Gregorio; et al Actores sociales y reformas del bienestar. Madrid: Consejo Superior de Investigaciones Científicas, Unidad de Políticas Comparadas, 2006. 194 p.

Rodríguez Cabrero, Gregorio. La protección social de las personas dependientes como desarrollo del estado del bienestar en España. Panorama social. 2005, n. 2, p. 21-33

Rodríguez Cabrero, Gregorio. La protección social de la dependencia en España. Fundación Alternativas n. ${ }^{\circ}$ 44//2004.

Rodríguez Cabrero, Gregorio; Renes Ayala, Víctor (coord.). La protección social de la dependencia en España. Documentación social. 2006, n. 141, p. 3-171

Rodríguez Rodríguez, Pilar. El Sistema de Servicios Sociales español y las necesidades derivadas de la atención a la dependencia. Fundación Alternativas n. ${ }^{\circ}$ 87/2006.

Sociedad Española de Geriatría y Gerontología. Saber envejecer: prevenirla dependencia. Madrid: Sociedad Española de Geriatría y Gerontología, 2005. 1 carpeta con 10 folletos.

Vincent, John; Phillipson, Chris; DOWNS, Murna (ed.). The futures of old age. London: Sage Publications, 2006. XV, 255 p. 